\title{
Size Effect on the Seismic Performance of High-Strength Reinforced Concrete Columns with Different Shear Span-to-Depth Ratios
}

\author{
Chunyi Yu, ${ }^{1}$ Hua Ma $\mathbb{D}^{1},{ }^{1}$ Yongping Xie $\mathbb{D}^{2},{ }^{2}$ Zhenbao Li $\mathbb{D}^{1},{ }^{1}$ and Zhenyun Tang $\mathbb{D}^{1}$ \\ ${ }^{1}$ The Key Laboratory of Urban Security and Disaster Engineering, Ministry of Education, Beijing University of Technology, \\ Beijing 100124, China \\ ${ }^{2}$ College of Exploration Technology and Engineering, Hebei GEO University, Shijiazhuang 050031, China
}

Correspondence should be addressed to Yongping Xie; axypa@163.com

Received 14 October 2018; Accepted 5 December 2018; Published 19 December 2018

Academic Editor: Jan Vorel

Copyright (C) 2018 Chunyi Yu et al. This is an open access article distributed under the Creative Commons Attribution License, which permits unrestricted use, distribution, and reproduction in any medium, provided the original work is properly cited.

\begin{abstract}
The size effect on the seismic performance of conventional reinforced concrete columns has been observed in terms of flexural failure and shear failure. Under earthquake loading, slender columns experience flexural failure, and short columns experience flexure-shear failure and shear failure. However, the effect of section size on the seismic performance of high-strength reinforced concrete columns under the conditions of different shear span-to-depth ratios requires further confirmation. For this purpose, six high-strength reinforced concrete columns with shear span-to-depth ratios of 2 and 4 were subjected to cyclic loading in this study. The experimental results indicated that relative nominal flexural strength, energy dissipation coefficient, factor of safety, and local factor of safety all exhibited a strong size effect by decreasing with increasing column size. Furthermore, the size effect became stronger as the shear span-to-depth ratio was increased, except for average energy dissipation coefficient. The observed changes in the factor of safety were in good agreement with the Type 2 size effect model proposed by Bažant. Thus, based on the local factor of safety and Bažant's Type 2 model, the code equation for moment capacity of different shear span-to-depth ratios was modified to provide a consistent factor of safety regardless of column size.
\end{abstract}

\section{Introduction}

Under the action of seismic activities, reinforced concrete (RC) columns (e.g., bridge piers and middle columns of underground structures) would bear not only the vertical and lateral loads but also the torsional effect [1]. Slender columns and short columns possess sufficient ductility considering the conditions of satisfying the shear bearing capacity of inclined sections. However, the shear deformation ratio and angle of the flexure-shear crack are large for short columns because of their small shear span-to-depth ratio. For slender columns, the flexural deformation ratio is large and the angle of the flexure-shear crack is small. For example, flexural failure, flexure-shear failure, and shear failure were observed in such columns during the Wenchuan earthquake $[2,3]$. In the event of strong seismic activity, structures with serious damage to the main bearing members would collapse, leading to serious loss of life and property. Therefore, structural bearing capacity is an important safety concern for designers. Current design codes, including the Chinese code [4] and ACI code [5], are based on the theory of limit states justified by the theory of plasticity, which implies that the code provisions for moment capacity do not consider size effect. Nevertheless, existing theories [6-14] demonstrate that the size of columns affect their seismic performance. A large number of experimental results have demonstrated existence of the size effect in plain and reinforced concrete components, such as plain concrete columns $[15,16]$, RC beams [17-19], RC columns [20-22], and RC beam-column joints [23, 24]. Moreover, the size effect is significantly stronger in highstrength reinforced concrete deep beam with large shear span-to-depth ratio than that with small shear span ratio [17]. 
TABLE 1: Mix proportions of concrete.

\begin{tabular}{lcccc}
\hline Grade number & Water $\left[\mathrm{kg} / \mathrm{m}^{3}\right]$ & Cement $\left[\mathrm{kg} / \mathrm{m}^{3}\right]$ & Sand $\left[\mathrm{kg} / \mathrm{m}^{3}\right]$ & $\mathrm{Gravel}\left[\mathrm{kg} / \mathrm{m}^{3}\right]$ \\
\hline C60 & 158 & 395 & 672 & 1051 \\
\hline
\end{tabular}

TABLE 2: Material properties of concrete.

\begin{tabular}{lcccc}
\hline Batch & Grade number & $\begin{array}{c}\text { Prismatic specimen size } \\
{\left[\mathrm{mm}^{3}\right]}\end{array}$ & $f_{t k}[\mathrm{MPa}]$ & $f_{c k}[\mathrm{MPa}]$ \\
\hline First & C60 & $150 \times 150 \times 300$ & 3.48 & 48.77 \\
Second & C60 & $150 \times 150 \times 300$ & 3.76 & 49.67 \\
\hline
\end{tabular}

$f_{t k}$ : concrete tensile strength; $f_{c k}$ : concrete compressive strength.

However, for columns with different shear span-to-depth ratios, the size effect on the seismic performance of highstrength RC columns remains to be clarified.

The effect of structural size on nominal strength is an old problem [6]. The structural ultimate load predicted by any deterministic strength theory (e.g., the elastic, plastic, or elastoplastic strength criteria) applied to ductile materials exhibits no size effect. In 1921, Griffith [7] proposed linear elastic fracture mechanics (LFEM) and introduced fracture mechanics into the study of the size effect. For brittle, geometrically similar structures, LEFM shows that nominal strength decreases as structure size increases, following the trend of an inclined asymptote with a slope of $-1 / 2$. Then, Weibull $[8,9]$ derived an equation capturing the size effect on mean structural strength based on the Weibull distribution. This approach is certainly valid for various fine-grain ceramics and metal structures embrittled by fatigue. Bažant identified the Type $1[6,12]$, Type $2[10]$, and universal size effect laws [13]. These laws are suitable for quasi-brittle materials, such as plain and reinforced concrete components, whose properties are between those of ductile and brittle materials. In recent research, Hoover et al. [14] established an improved universal size effect model. Considering the absence or presence of a statistical size effect, the improved universal size effect model can be divided into two types. The relationship between these various size effect models has been described in the literature $[25,26]$. In addition to the nominal strength derived from deterministic strength theory, all models show that the nominal strength decreases with the increase of the component size.

Research on the size effect of reinforced concrete column has been focused on conventional concrete [27-29], including specimens with shear span-to-depth ratios of 2 and 4. The former experience shear failure, and the latter experience flexural failure. The relative nominal shear strength, energy dissipation coefficient, factor of safety, and nominal flexural strength were found to decrease as the section size increased, showing a pronounced size effect. However, systematical analyses of the size effect on the seismic performance of high-strength RC columns with different shear span-to-depth ratios have rarely been performed. Yang et al. [17] found that high-strength reinforced concrete deep beams with a shear span-to-depth ratio of 0.5 were less sensitive to the size effect than those with a shear span-to-depth ratio of 1 .
However, the effect of section size on the seismic performance of high-strength reinforced concrete columns under the conditions of different shear span-to-depth ratios requires further confirmation.

In this study, high-strength RC columns with different shear span-to-depth ratios were subjected to cyclic loading. Based on test results, the failure behavior and size effect rule for different seismic parameters were obtained, and the size effect on the seismic performance of high-strength RC columns with different span-to-depth ratios was confirmed. In total, six high-strength RC columns were investigated experimentally, maintaining geometrically proportional sizes of the materials and components. For short columns with a shear span-to-depth ratio of 2 , the section sizes of the tested specimens were 300,500 , and $700 \mathrm{~mm}$, and the column lengths were 546, 910, and $1274 \mathrm{~mm}$. For slender columns with a shear span-to-depth ratio of 4 , the section sizes of tested specimens were same as mentioned above, but the column lengths were 1092, 1820, and $2548 \mathrm{~mm}$.

\section{Experimental Program}

2.1. Material Properties. The mixture proportions of the concrete adopted in this study are listed in Table 1. The type of cement was P42.5 Portland cement, and the mix consisted of medium sand as the fine aggregate (average diameter of $2.7 \mathrm{~mm}$ ) and crushed pebble stones as the coarse aggregate (average diameter of 5-25 mm). The slump of the concrete was $160 \pm 20 \mathrm{~mm}$. The material properties of concrete are summarized in Table 2 . Tested according to the Chinese Standards for the mechanical properties of concrete (GB/T 50081-2002) [30], the average compressive strengths of standard 150-mm cubic concrete samples were 65.57 and $67.98 \mathrm{MPa}$, respectively, the average compressive strengths of standard $150 \times 150 \times 300 \mathrm{~mm}$ prismatic concrete samples were 48.77 and $49.67 \mathrm{MPa}$, respectively, and the average tensile strengths of standard $150 \times 150 \times 150 \mathrm{~mm}$ cubic concrete samples were 3.48 and $3.76 \mathrm{MPa}$, respectively. Due to a large amount of casting, it was divided into two batches. Thus, there were two types of concrete strength.

The material properties of the steel rebar used in the test specimens are listed in Table 3. Material properties, including yield strength, ultimate tensile strength, modulus of elasticity, and yield strain, were determined according to the Chinese 
TABLE 3: Material properties of rebar.

\begin{tabular}{lccccc}
\hline Bar size $[\mathrm{mm}]$ & Bar grade & Yield strength $[\mathrm{MPa}]$ & Ultimate strength $[\mathrm{MPa}]$ & Modulus of elasticity $[\mathrm{MPa}]$ & Yield strain $\left(\times 10^{-6}\right)$ \\
\hline 6 & HPB300 & 441 & 690 & 251657 & 1752 \\
10 & HPB300 & 346 & 501 & 197265 & 1779 \\
14 & HPB300 & 351 & 490 & 199279 & 1736 \\
12 & HRB400 & 478 & 625 & 196752 & 2429 \\
20 & HRB400 & 451 & 595 & 195233 & 2310 \\
28 & HRB400 & 455 & 636 & 191655 & 2374 \\
\hline
\end{tabular}

HPB: plain reinforcement; HRB: deformed bar reinforcement.

TABLE 4: Details of specimens and bars.

\begin{tabular}{|c|c|c|c|c|c|c|c|c|c|}
\hline Test no. & $b[\mathrm{~mm}]$ & $h[\mathrm{~mm}]$ & $H[\mathrm{~mm}]$ & $f_{\mathrm{ck}}[\mathrm{MPa}]$ & Concrete cover [mm] & $\lambda$ & Stirrup & Longitudinal bar & $\rho[\%]$ \\
\hline WF-3-2 & 300 & 300 & 546 & 48.77 & 15 & 2.00 & 4A6@43 & $12 \mathrm{C} 12$ & 0.55 \\
\hline WF-5-2 & 500 & 500 & $910+300$ & 48.77 & 25 & 2.66 & 4A10@71 & $12 \mathrm{C} 20$ & 0.55 \\
\hline WF-7-2 & 700 & 700 & $1274+300$ & 48.77 & 35 & 2.47 & 4A14@100 & $12 \mathrm{C} 28$ & 0.55 \\
\hline WF-3-4 & 300 & 300 & 1092 & 49.67 & 15 & 4.00 & 4A6@43 & $12 \mathrm{C} 12$ & 0.55 \\
\hline WF-5-4 & 500 & 500 & $1820+300$ & 49.67 & 25 & 4.66 & 4A10@71 & $12 \mathrm{C} 20$ & 0.55 \\
\hline WF-7-4 & 700 & 700 & $2548+300$ & 49.46 & 35 & 4.47 & 4A14@100 & $12 \mathrm{C} 28$ & 0.55 \\
\hline
\end{tabular}

WF-3-2: a flexural component subjected to cyclic loading (the corresponding numbers represent cross sectional dimensions of the specimen in hundreds of millimeters and shear span-to-depth ratio); $b$ and $h$ : cross sectional dimensions; $H$ : total height of the column and spherical hinge ( +300 represents spherical hinge height); $f_{\mathrm{ck}}$ : axial compressive strength of the concrete. Shear span-to-depth ratio $\lambda$ is given by $H / h_{0}$, and $\rho$ is determined by $A_{s} /\left(b h_{0}\right)$, where $A_{s}$ is the required tensile or compressive steel area and $h_{0}$ is the effective depth of the column.

standard for determining the mechanical properties of steel (GB/T 228.1-2010) [31].

2.2. Specimen Description. The sizes of the tested columns were 300,500 , and $700 \mathrm{~mm}$, and the longitudinal bar size and spacing, stirrup size, and thickness of concrete cover of each specimen were scaled proportionally according to the column size. The details of the specimens and bars are provided in Table 4, along with an explanation of test specimen nomenclature. Reinforcement details and column dimensions are shown in Figure 1, including the specimens with shear span-to-depth ratios of 2 and 4 .

\subsection{Loading Apparatus and Loading Scheme}

2.3.1. Loading Apparatus. A total of six high-strength RC columns of three different structural sizes were investigated experimentally. The $300-\mathrm{mm}$ specimens were tested using small range actuators (shown in Figure 2(a)) that provided vertical and horizontal maximum loads of $2000 \mathrm{kN}$ and 500 $\mathrm{kN}$. However, because the axial compression of the other specimens was very large, the loading apparatus in Figure 2(a) could not provide sufficient axial loading. Thus, the 500- and 700-mm specimens were tested in a slightly different configuration with more powerful large range actuators (Figure 2(b)) that provided vertical and horizontal maximum loads of $40000 \mathrm{kN}$ and $4000 \mathrm{kN}$. The axial load was provided by the vertical actuator, and the horizontal load was provided by the horizontal actuator. Displacement was measured using an LVDT in the locations shown in Figure 2, and the measured $H_{0}$ was used as the theoretical height of the column in later calculations.
2.3.2. Loading Scheme. The horizontal load simulated the effect of seismic action in the form of cyclic loading, while the vertical load applied by the actuator was held constant at an axial load ratio of 0.4 for the entire test as the specimen was loaded horizontally until failure. The load-displacement hybrid control method was used in the loading system: prior to specimen yielding, the load was applied in load increments, while, after yielding, the load was applied in displacement increments.

For columns subjected to cyclic loading, the horizontal load was applied to the columns at 20, 40, 60, 80, and $100 \%$ of the yield load. After reaching the yield load, the displacement at yield, $\Delta_{\mathrm{y}}$ was used to set the applied horizontal displacement control load in multiples, i.e., $\Delta_{y}, 1.5 \Delta_{y}, 2 \Delta_{y}$, $2.5 \Delta_{y} \ldots \ldots n \Delta_{\mathrm{y}}$, until failure, defined as the decrease in the apparent load capacity to $85 \%$ of the maximum supported load [32]. For specimens subjected to cyclic loading, one cycle was applied at each preyield load level and two cycles were applied at each postyield displacement level. The loading scheme is described in Figure 3.

2.3.3. Arrangement of Strain Gauges. The strains in the longitudinal bars and stirrups were measured using strain gauges at the locations shown in Figure 4. Then the stressstrain relationship of the steel was used to compute the bar stresses to verify the force in and deformation of the specimens. For longitudinal bars, five levels of strain gauges were applied at the column height for all columns. For the stirrups of short columns, 4 levels were applied, and for the slender columns, 2 levels were applied. 


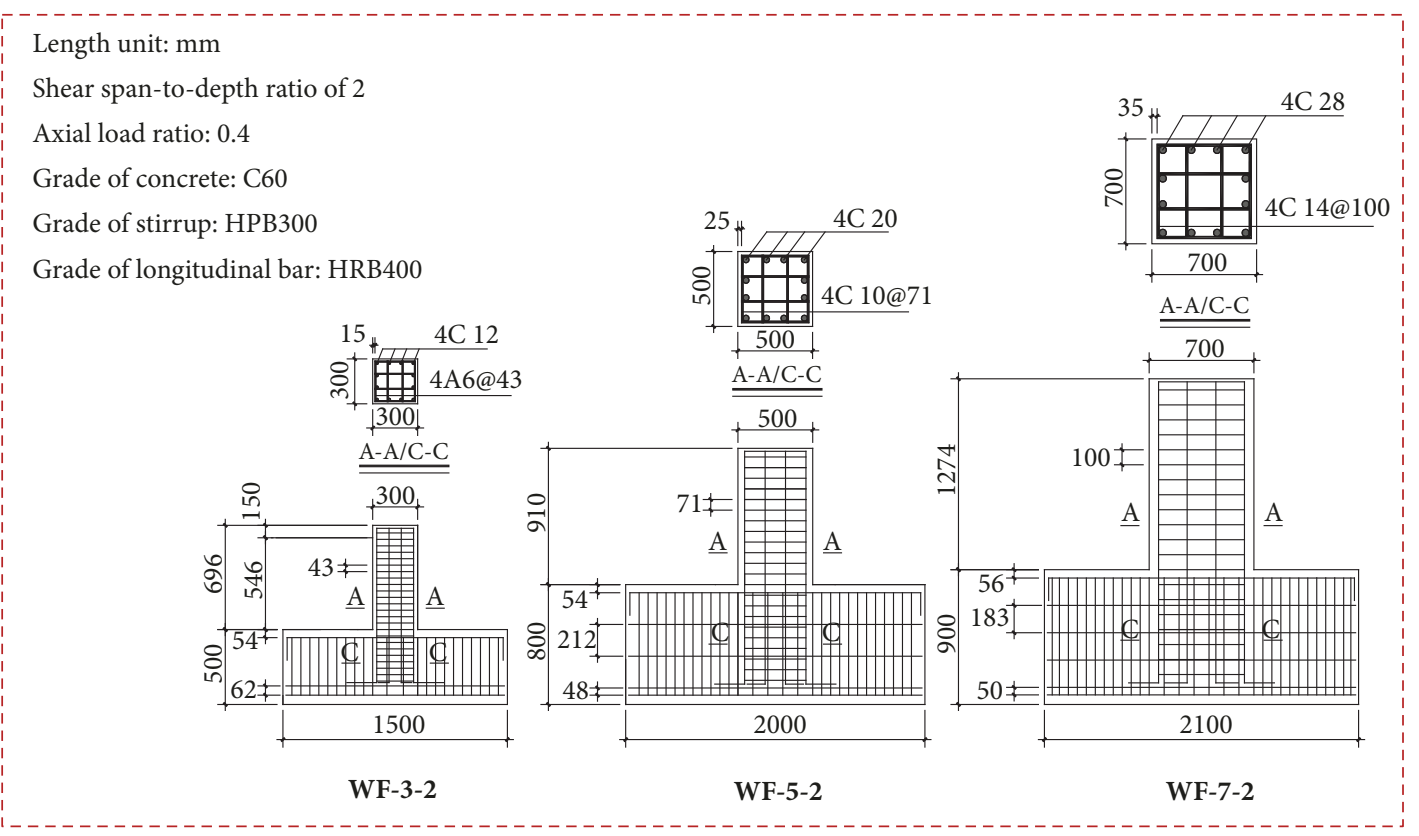

(a) Specimens with a shear span-to-depth ratio of 2

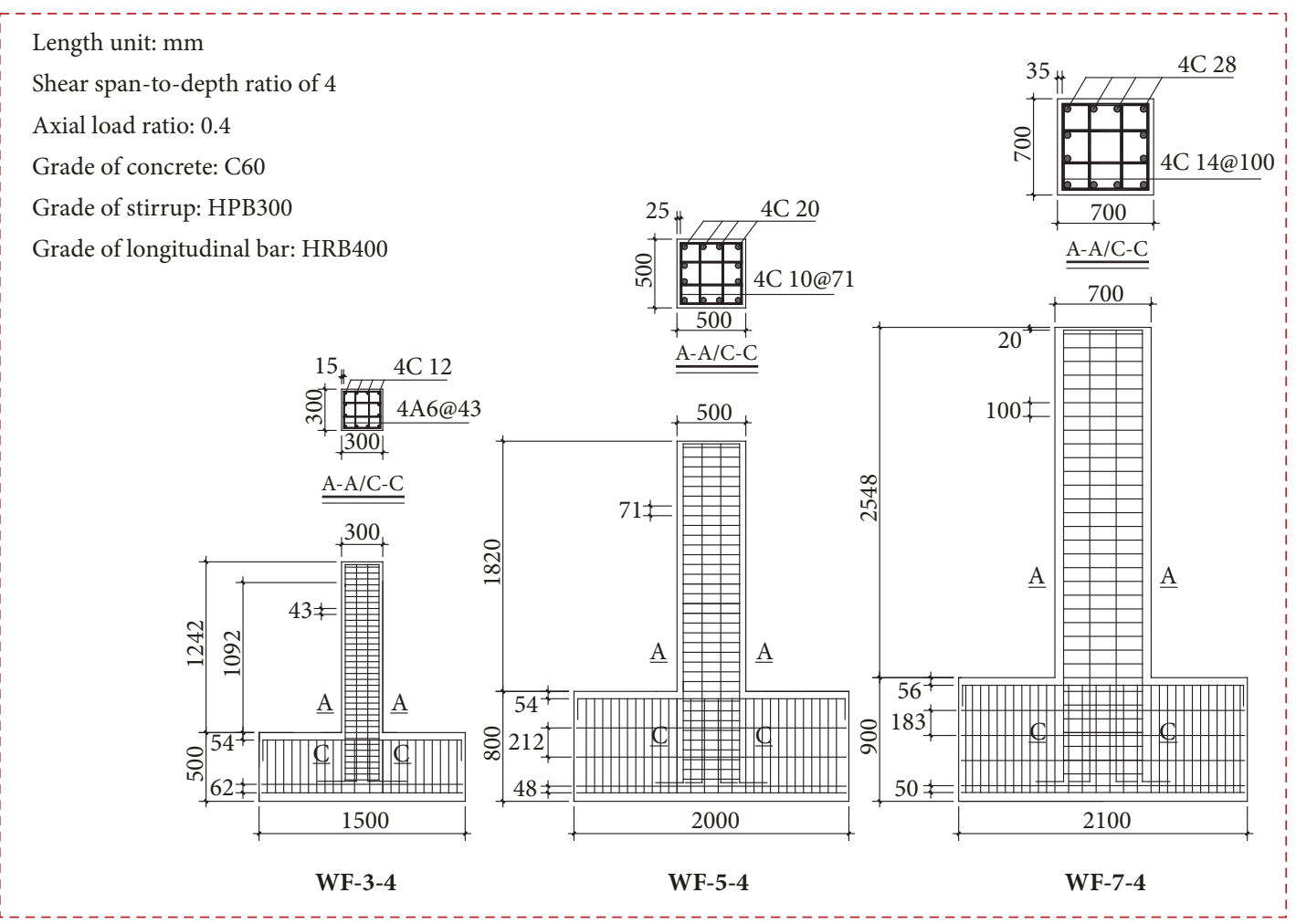

(b) Specimens with a shear span-to-depth ratio of 4

FIGURE 1: Details of the tested RC columns.

\section{Results and Discussion}

\subsection{Failure Modes}

3.1.1. Cyclic Specimens with a Shear Span-to-Depth Ratio of 2. The development of the failure modes under cyclic loading of the specimens with a shear span-to-depth ratio of 2 is shown in Figure 5. It includes three stages: yield load, maximum load, and failure load. Three main types of cracks were mainly observed, including flexure-shear cracks, splitting cracks, and few bond cracks. The location of failure on tested columns was in the plastic hinge region. The size of grid was $50 \mathrm{~mm}$, 


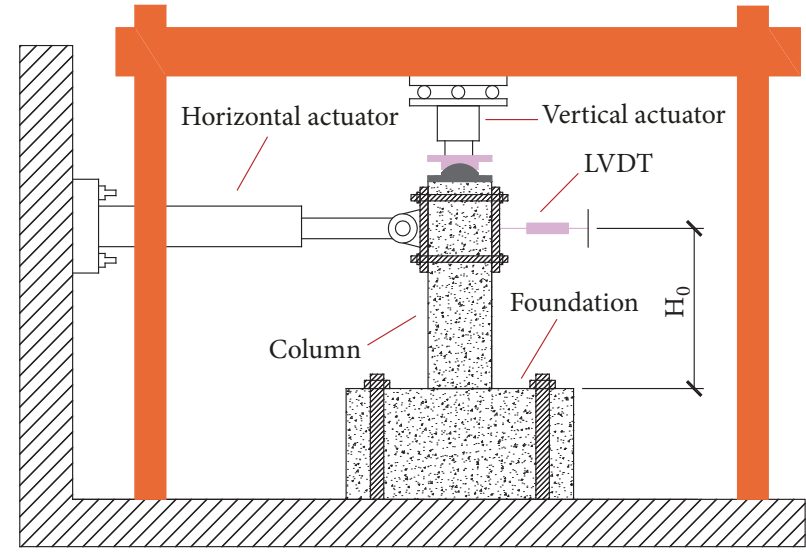

(a) Loading apparatus of $300-\mathrm{mm}$ specimens

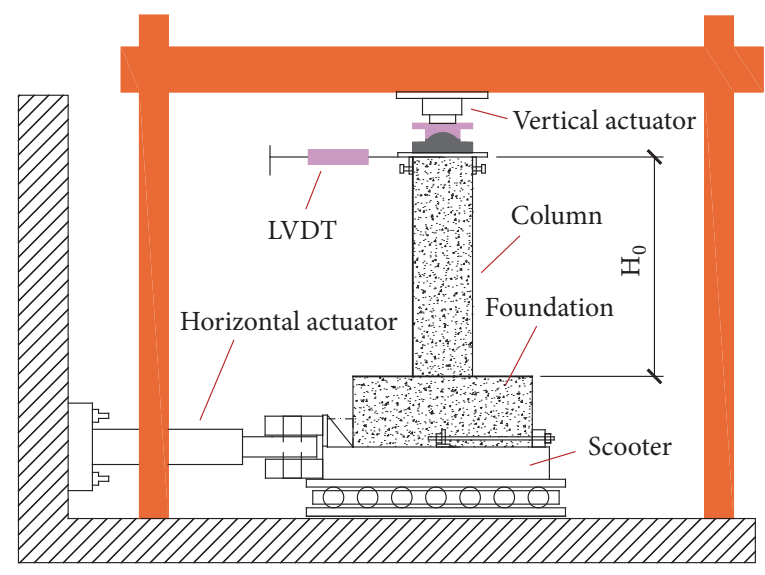

(b) Loading apparatus of 500- and 700-mm specimens

FIGURE 2: Loading apparatus for all specimens.

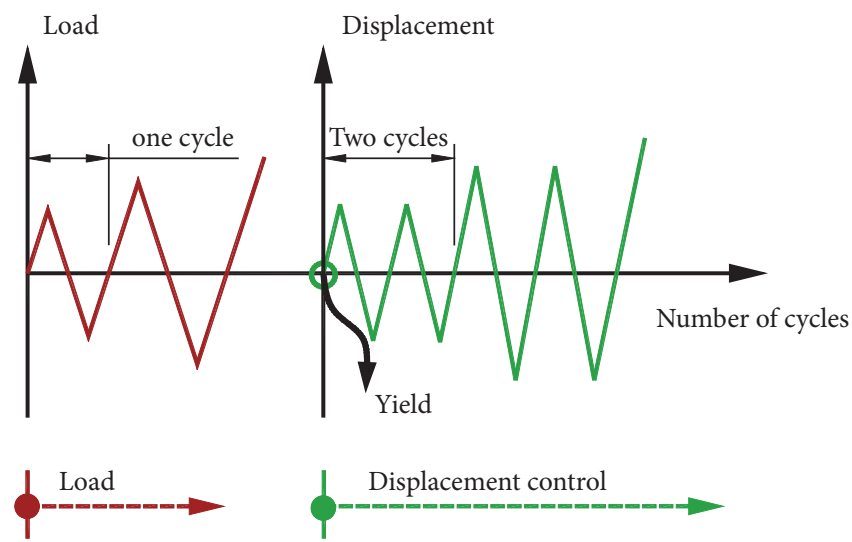

Figure 3: Cyclic loading scheme for specimens.

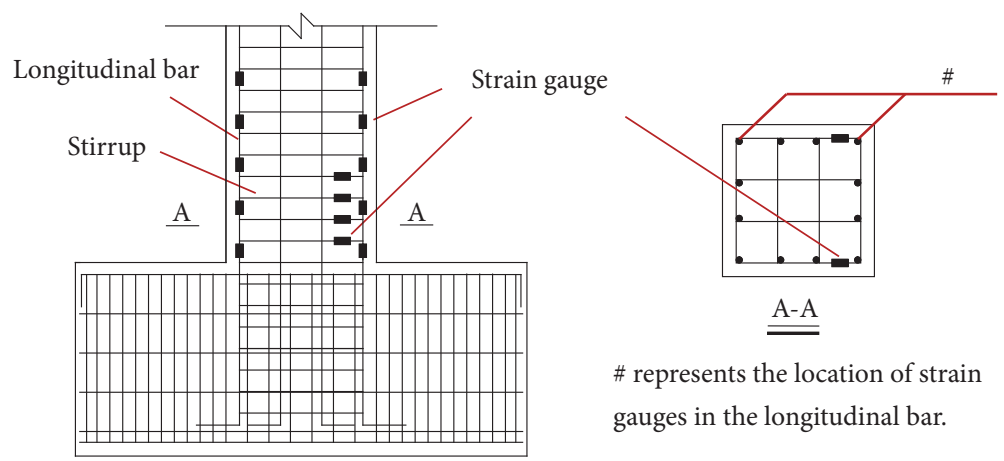

FIGURE 4: Strain measurement points in the longitudinal bars and stirrups.

which reflected the heights of failure. For WF-3-2, WF-5-2, and WF-7-2, the heights of failure were approximately 300 , 910, and $1274 \mathrm{~mm}$.

(1) A horizontal crack occurred in the position of the maximum moment when the yield load was reached. Meanwhile, there were flexure-shear cracks in the upper portion of the specimens. Moreover, for specimen WF-7-2, bond cracks that might be caused by the slip between longitudinal steel bar and concrete were observed in the position of the center longitudinal rebar (Figure 5(c)). When the load reached the failure load, the number of flexure-shear cracks increased, and the angle of flexure-shear cracks was approximately $65^{\circ}$ in the upper portion.

(2) The development of vertical splitting cracks was similar in different sized specimens. A vertical short splitting crack was first produced in the compression zone when the 

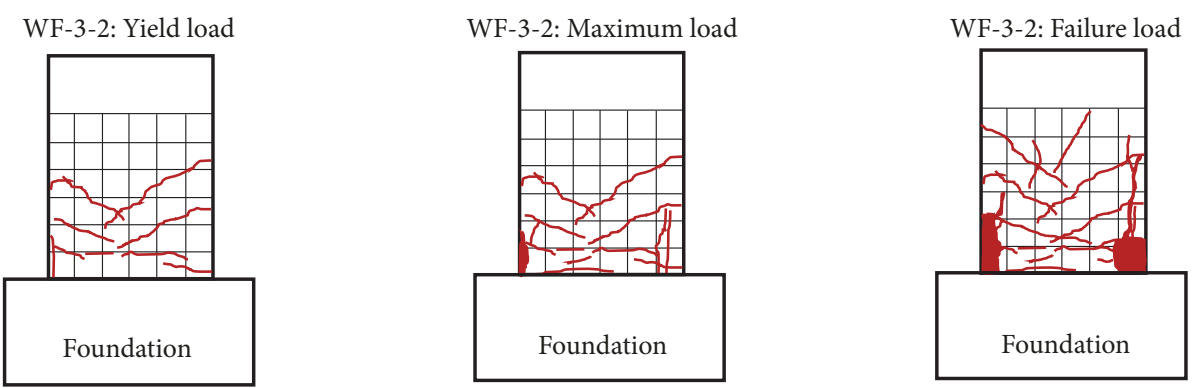

(a) Development of failure modes of WF-3-2 specimen

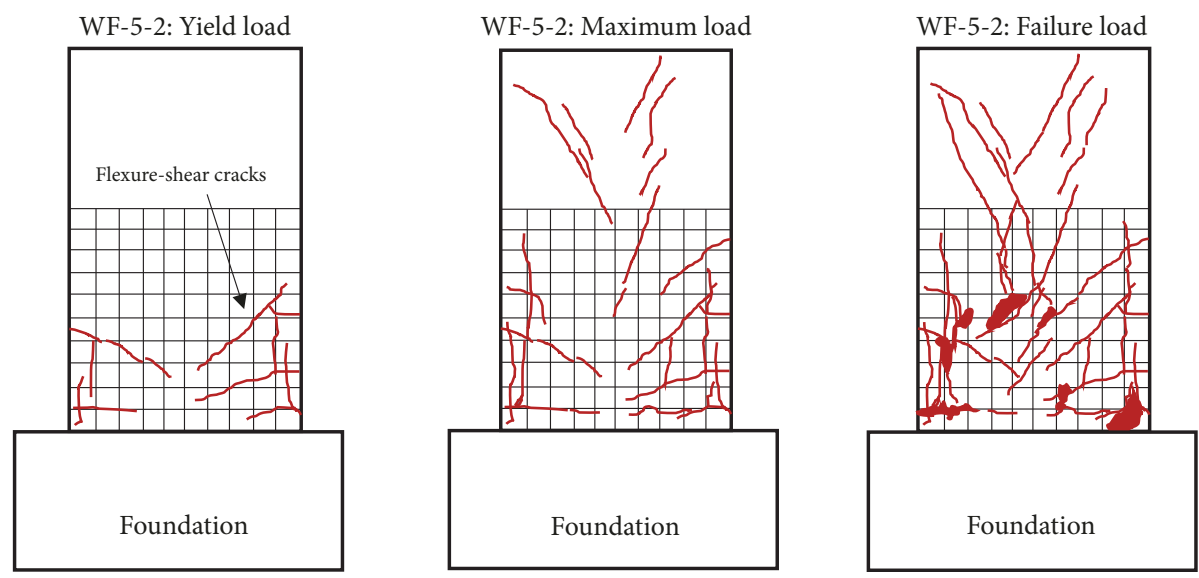

(b) Development of failure modes of WF-5-2 specimen
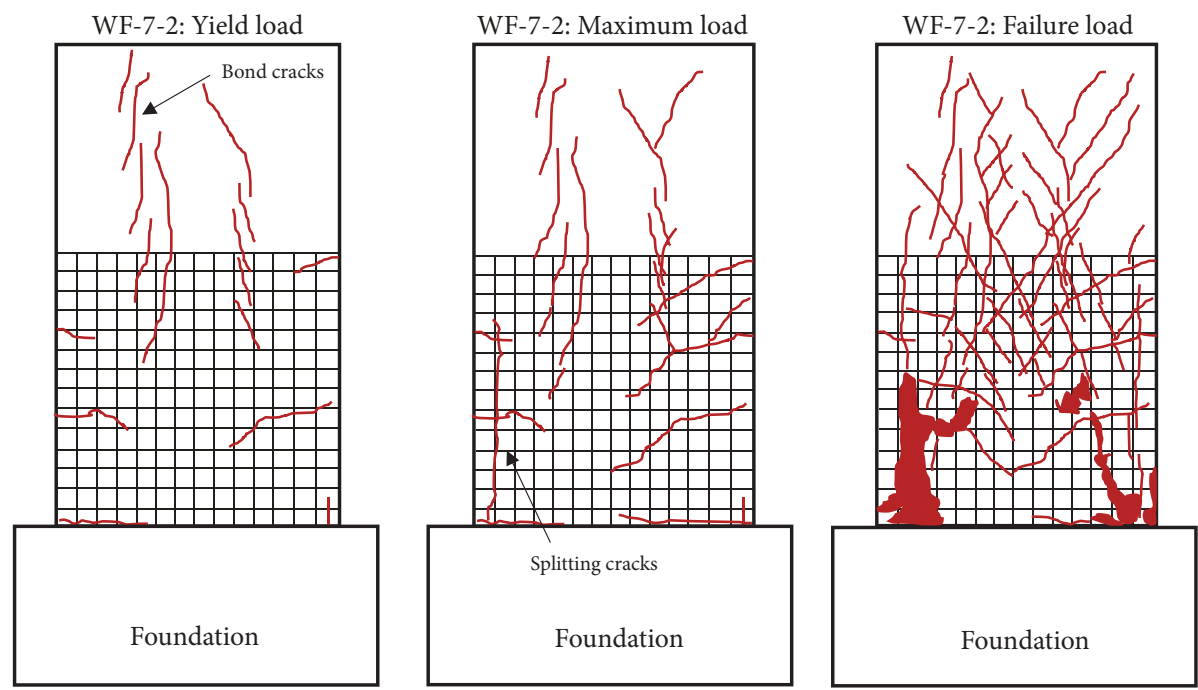

(c) Development of failure modes of WF-7-2 specimen

FIGURE 5: Development of failure modes for shear span-to-depth ratio of 2.

yield load was reached. Once the maximum load was reached, relative obvious vertical splitting cracks were produced in specimen WF-7-2. Then, when the failure load was reached, the vertical splitting cracks widened, and extended upward, ultimately crushing the concrete in the compressive zone at failure.

3.1.2. Cyclic Specimens with a Shear Span-to-Depth Ratio of 4. The development of the failure modes of the specimens with a shear span-to-depth ratio of 4 under cyclic loading is shown in Figure 6. It includes three stages: yield load, maximum load, and failure load. Two types of cracks mainly occurred, including flexure-shear cracks and splitting cracks. The location of failure on tested columns was in the plastic hinge region. The size of grid was $50 \mathrm{~mm}$, which reflected the heights of failure. For WF-3-4, WF-5-4, and WF-74 , the heights of failure were approximately 300, 850, and $1200 \mathrm{~mm}$. 

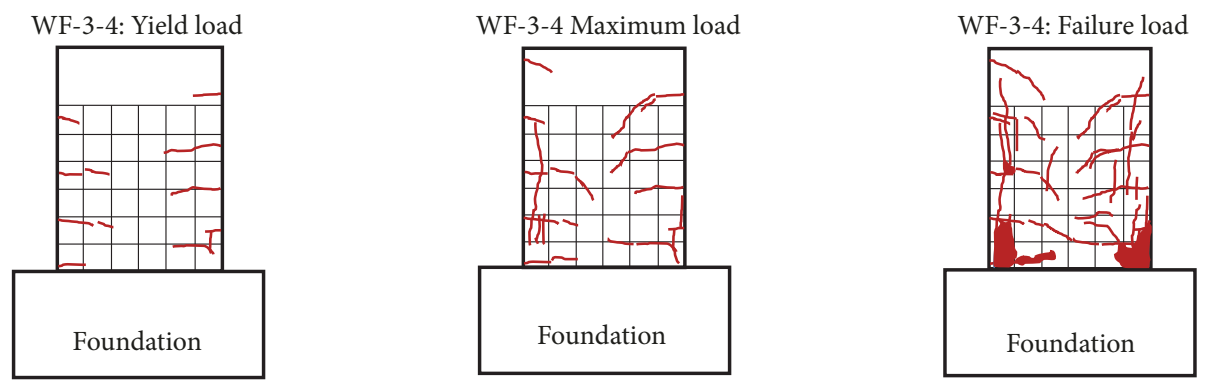

(a) Development of failure modes of WF-3-4 specimen
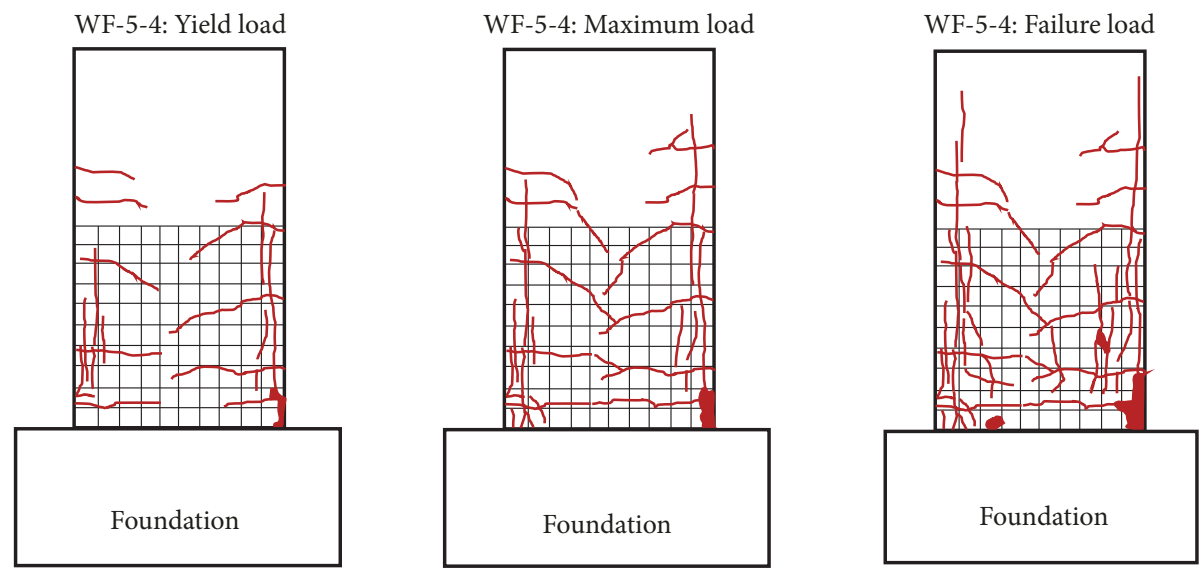

(b) Development of failure modes of WF-5-4 specimen
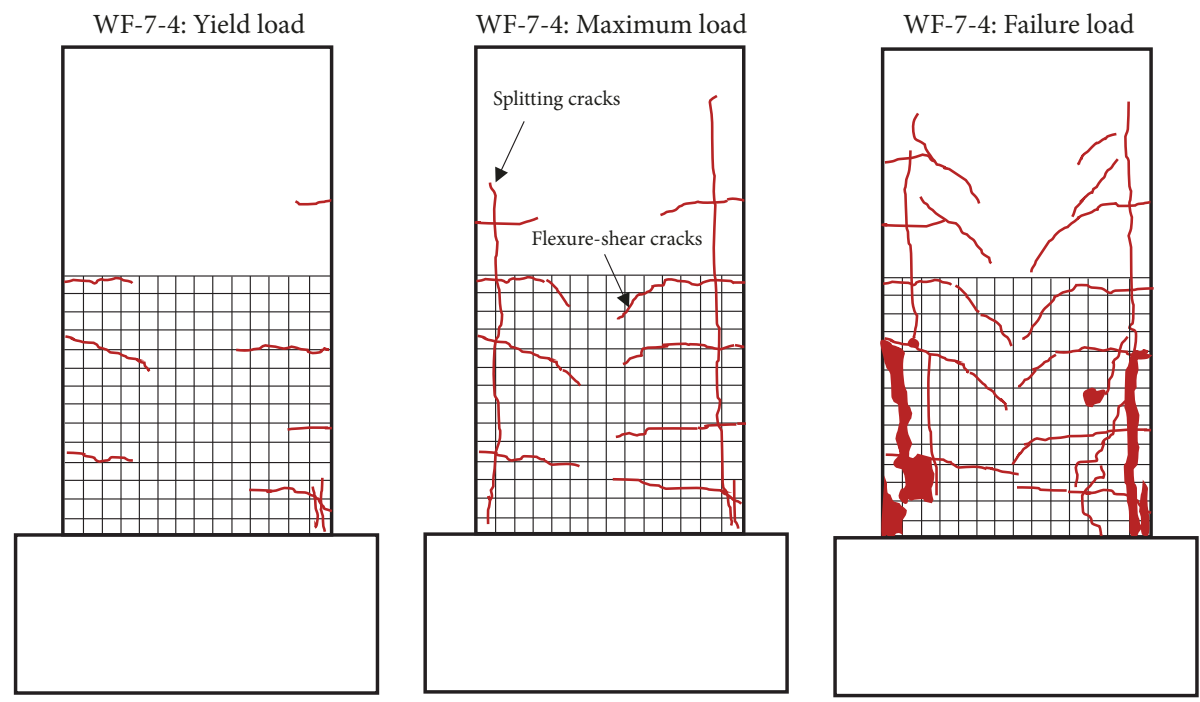

(c) Development of failure modes of WF-7-4 specimen

FIGURE 6: Development of failure modes for shear span-to-depth ratio of 4.

(1) As the applied load increased, the angle of the flexure-shear cracks increased. When the load reached its maximum value, the angle of the flexure-shear cracks reached approximately $45^{\circ}$ and then remained constant. Once the failure load was reached, the horizontally projected lengths of the flexure-shear cracks were approximately equal to half the column width. Finally, about five flexure-shear cracks appeared at failure, and the angle of flexure-shear cracks remained constant.
(2) With increasing displacement, the length and number of vertical splitting cracks increased. A vertical splitting crack was first produced in the compression zone when the yield load was reached. Once the maximum load was reached, more obvious vertical splitting cracks were produced. Then, when the failure load was reached, the vertical splitting cracks widened, extended upward, and developed into the neutral axis. Finally, crushing of the concrete was observed in the compressive zone at failure, with numerous splitting cracks. 
TABLe 5: Values of load and displacement for WF specimens.

\begin{tabular}{|c|c|c|c|c|c|c|c|c|}
\hline \multirow{2}{*}{ Test no. } & \multirow{2}{*}{ Direction } & \multicolumn{2}{|c|}{ Yield } & \multicolumn{2}{|c|}{ Maximum } & \multicolumn{2}{|c|}{ Failure } & \multirow{2}{*}{ Ductility coefficient } \\
\hline & & $P_{y}[\mathrm{kN}]$ & $\Delta_{y}[\mathrm{~mm}]$ & $P_{m}[\mathrm{kN}]$ & $P_{y}[\mathrm{kN}]$ & $\Delta_{y}[\mathrm{~mm}]$ & $P_{m}[\mathrm{kN}]$ & \\
\hline \multirow{2}{*}{ WF-3-2 } & Positive & 477 & 3.30 & 539 & 8.37 & 458 & 19.19 & 5.82 \\
\hline & Negative & 482 & 3.70 & 556 & 10.19 & 473 & 20.90 & 5.65 \\
\hline \multirow{2}{*}{ WF-5-2 } & Positive & 966 & 3.60 & 1128 & 5.71 & 959 & 15.66 & 4.35 \\
\hline & Negative & 981 & 2.70 & 1151 & 6.18 & 978 & 13.80 & 5.11 \\
\hline \multirow{2}{*}{ WF-7-2 } & Positive & 1879 & 5.30 & 2138 & 12.89 & 1817 & 19.99 & 3.77 \\
\hline & Negative & 2001 & 4.30 & 2272 & 6.57 & 1931 & 14.97 & 3.48 \\
\hline \multirow{2}{*}{ WF-3-4 } & Positive & 207 & 5.21 & 244 & 8.90 & 207 & 21.0 & 4.03 \\
\hline & Negative & 182 & 6.44 & 208 & 12.10 & 176 & 29.00 & 4.50 \\
\hline \multirow{2}{*}{ WF-5-4 } & Positive & 487 & 10.40 & 556 & 13.80 & 473 & 35.40 & 3.41 \\
\hline & Negative & 528 & 7.90 & 604 & 11.40 & 513 & 29.00 & 3.67 \\
\hline \multirow{2}{*}{ WF-7-4 } & Positive & 921 & 10.89 & 1054 & 14.70 & 896 & 40.07 & 3.68 \\
\hline & Negative & 882 & 9.30 & 1031 & 13.30 & 876 & 37.90 & 4.00 \\
\hline
\end{tabular}

In summary, as the shear span-to-depth ratio increased, the angle of flexure-shear cracks decreased, length of splitting cracks increased, and number of splitting cracks also increased. For the specimens with the shear span-to-depth ratio of 2, although the angle of the flexure-shear cracks was large, the compressive concrete was still dominated by flexural failure. For the specimens with the shear span-todepth ratio of 4 , failure was mainly dominated by flexural failure. Meanwhile, it is important to note here that a slenderer splitting length is different from that of the shear span-to-depth ratio of 2 . This difference may lead to the difference in the size effect between them. Moreover, for specimens with the shear span-to-depth ratios of 2 and 4, large stable crack growth was observed before reaching the maximum load [6], which is in accordance with Bažant's Type 2 size effect model [10].

3.2. Horizontal Load-Displacement Curves. Figure 7 shows the relationship between force and deformation for the specimens with shear span-to-depth ratios of 2 and 4 . The seismic parameter mainly includes energy dissipation and strength degradation factor (as shown in Figures 8 and 9). The following main characteristics could be observed.

(1) Dissipation energy in the area of the hysteresis loop increased as the displacement increased, and the extent of increase became obvious with large deformation of columns; as the section size increased the energy dissipation increased.

(2) Strength degradation factor at the ratio, that was defined as the ratio $P_{2}$ (second load) to $P_{1}$ (first load) under condition of same displacement, was a constant with small deformation of columns for the specimens with the shear span-to-depth ratio of 2 (Figure 9(a)). However, the strength degradation factor gradually decreased as the displacement increased with large deformation. For the specimens with the shear span-to-depth ratio of 4 (Figure 9(b)), the strength degradation factor was constant throughout the loading progress. In addition, the size of the cross section had no significant effect on the strength degradation factor for the two types of columns.
In summary, according to the design of bending failure, the energy dissipation ability was better. There was no pinchup phenomenon caused by the slip of the steel bar, which was advantageous to the resistance of the structures against earthquake action. In addition, for the short columns with the shear span-to-depth ratio of 2 , the strength degradation factor was unstable, which is unfavorable for the stability of the structure, and might even cause the collapse of the structure. However, for the slender columns with the shear span-to-depth of 4 , the strength degradation factor was stable, which is advantageous.

Based on the hysteresis curves, a skeleton curve could be obtained by taking the maximum load in the first cyclic loading stage of every load level, as shown in Figure 10. The bearing capacity of specimens with the shear span-to-depth ratio of 2 was approximately twice that of the shear span-todepth ratio of 4 , showing an increase in the horizontal bearing capacity of specimens with the decrease in shear span-todepth ratio. This also suggests that the relationship between shear force and shear span-to-depth ratio was inversely linear. In addition, these curves also exhibited a short plateau, especially for the larger-sized specimens of WF-7-2 and WF-7-4, reflecting the effect of the vertical splitting cracks on moment capacity, and thus these cracks should not be neglected as they might be linked to the size effect.

As shown in Figure 10, the initial cracking load of the specimens was not obvious, likely due to the influence of the axial load. Therefore, only the yield load, maximum load, and failure load are used as the characteristic points of the curve. The calculation of yield load and failure load is shown in Figure 11. The yield point $\mathrm{Y}$ was determined by the equivalent elastoplastic energy method, i.e., where the area $\mathrm{BYC}=\mathrm{OAB}$, and the failure load is simply defined as $85 \%$ of the maximum load [32]. The calculated loads and displacements are shown in Table 5, indicating that the calculated yield load is between $85 \%$ and $88 \%$ of the maximum load. In the table, the variables $P_{y}, P_{m}$, and $P_{u}$ indicate the yield load, maximum load, and failure load, respectively, while $\Delta_{y}, \Delta_{m}$, and $\Delta_{u}$ indicate the displacements at the yield, maximum, and failure loads, 


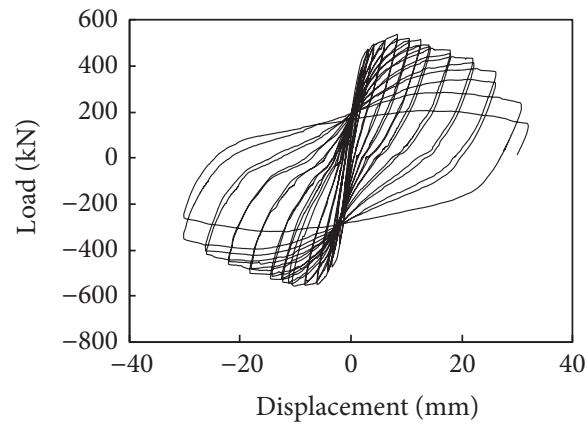

(A) WF-3-2

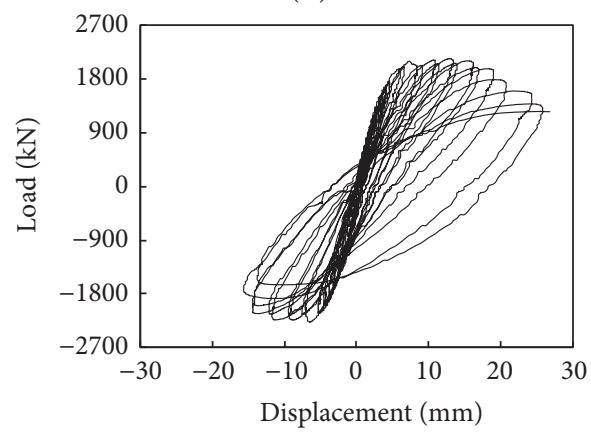

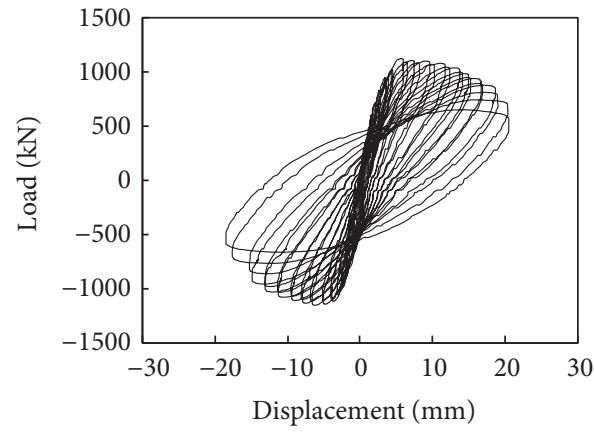

(B) WF-5-2

(C) WF-7-2

(a) Specimens with a shear span-to-depth ratio of 2

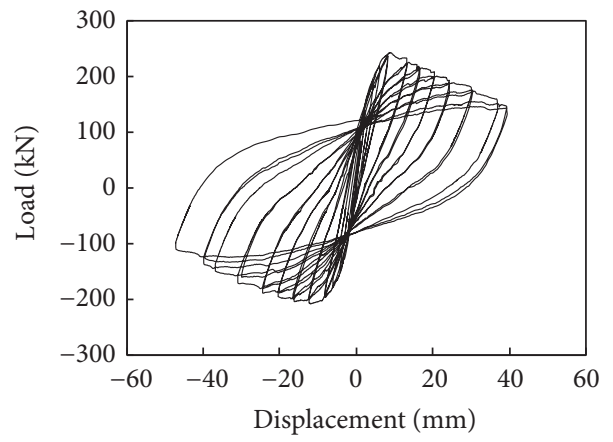

(A) WF-3-4

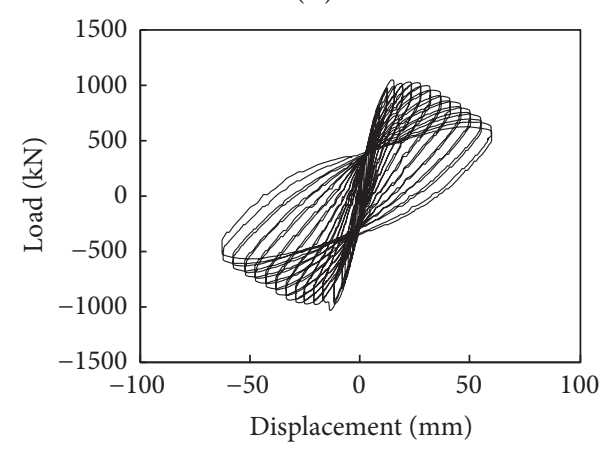

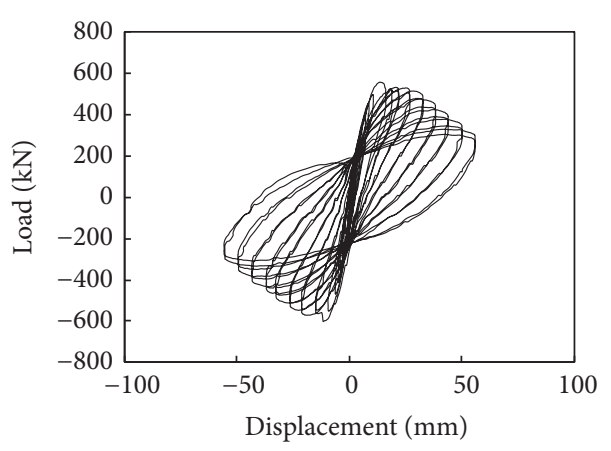

(B) WF-5-4

(C) WF-7-4

(b) Specimens with a shear span-to-depth ratio of 4

FIGURE 7: Hysteresis curves of specimens. 

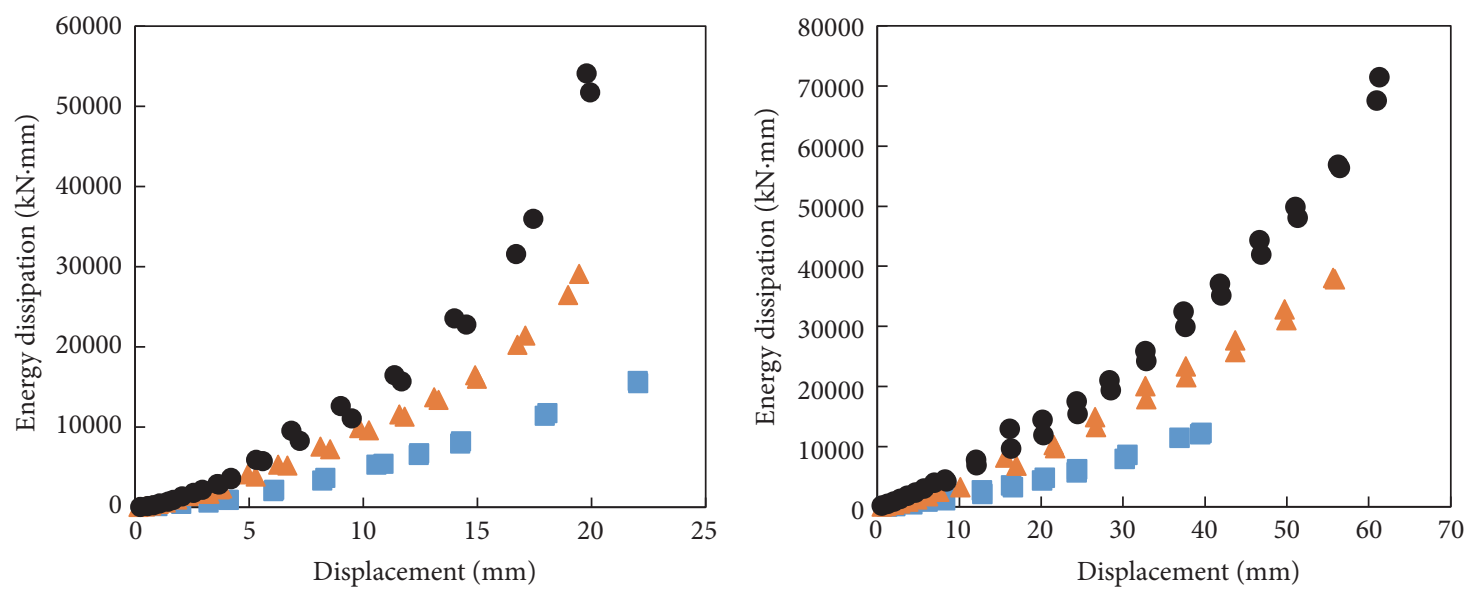

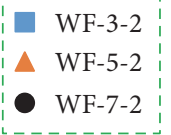

(a) Specimens with a shear span-to-depth ratio of 2

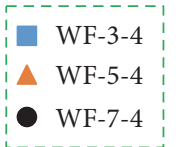

(b) Specimens with a shear span-to-depth ratio of 4

FIGURE 8: Relationship between energy dissipation and displacement.
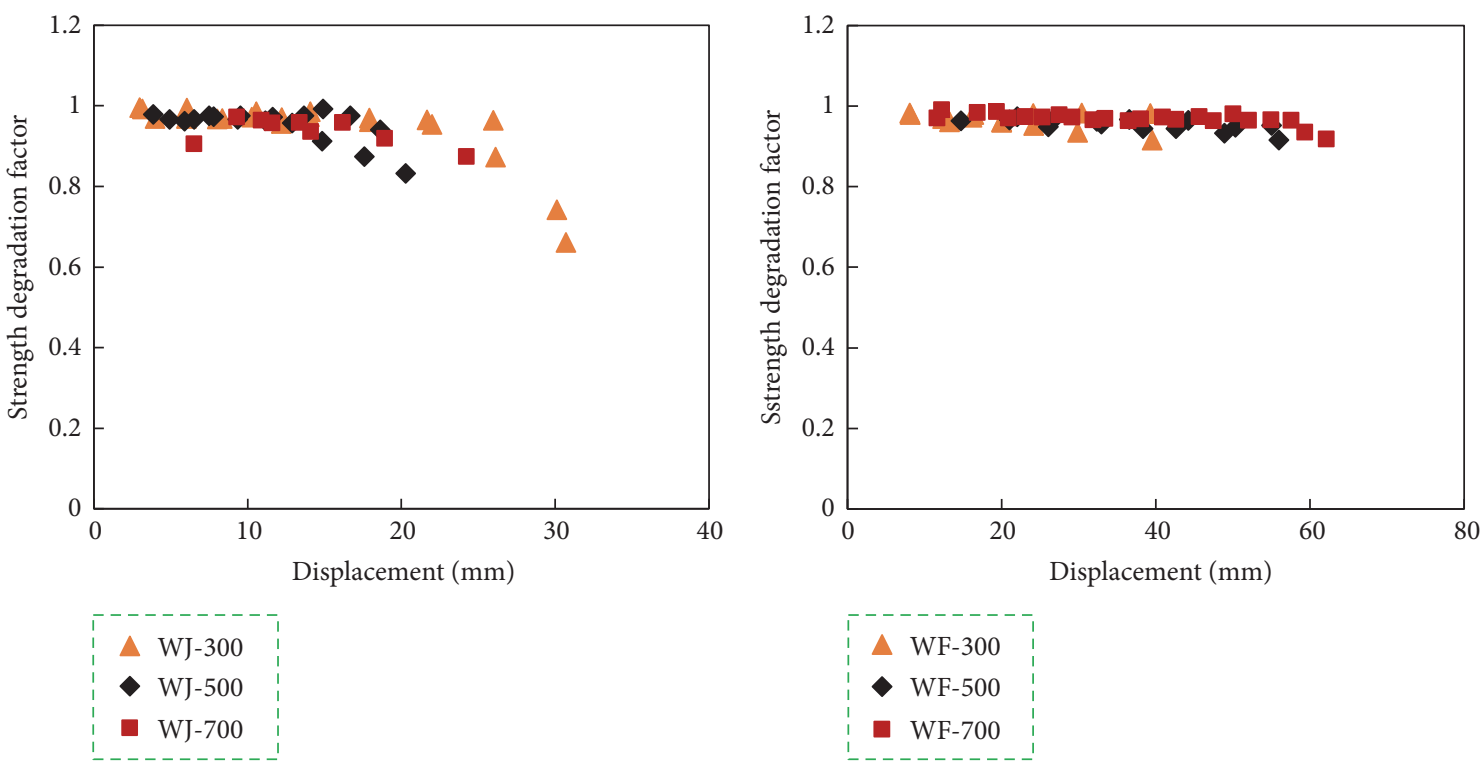

(a) Specimens with a shear span-to-depth ratio of 2

(b) Specimens with a shear span-to-depth ratio of 4

FIGURE 9: Relationship between strength degradation factor and displacement.

respectively. Moreover, for the specimens with the shear span-to-depth ratio of 2 , the ductility coefficient-the ratio of failure displacement to yield displacement [30] — was slightly larger than that of the specimens with the shear span-todepth ratio of 4 , indicating that the ductility of the short columns is sufficient under the condition of guaranteeing the shear bearing capacity of inclined cross section.

3.3. Analysis of Strain in Longitudinal Bars and Stirrups. The strains in the longitudinal bars and stirrups for the specimens of shear span-to-depth ratios of 2 and 4 are given in Table 6. The following characteristics were observed:

(1) For the all cyclic WF specimens, the strain in the longitudinal bars reached the yield strain, but only the stirrups in specimen WF-3-4 reached partial yield.

Generally, the overall mechanical behavior of the reinforcement was characterized by the strain in the longitudinal bars reaching the yield strain but not the strain in the stirrups, indicating that the likely final failure mode of the specimens would be flexure before shear. 

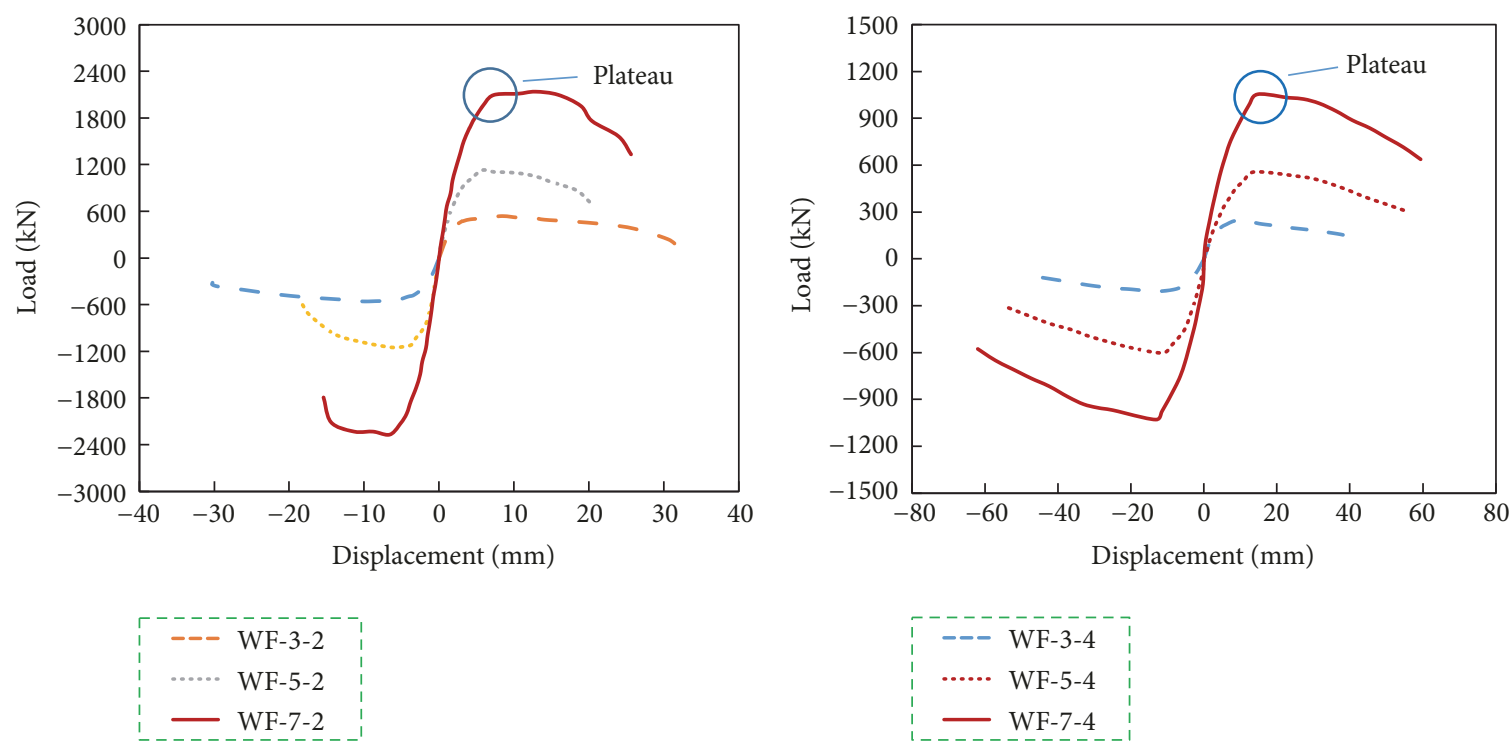

(a) Specimens with a shear span-to-depth ratio of 2

(b) Specimens with a shear span-to-depth ratio of 4

FIGURE 10: Skeleton curves of WF specimens.

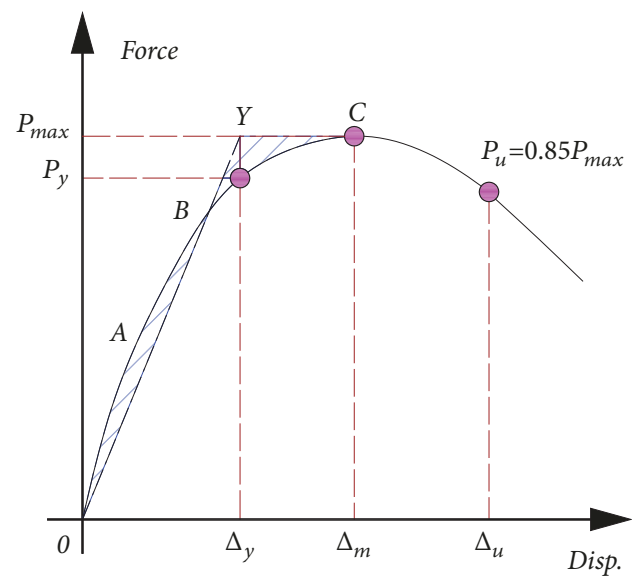

FIGURE 11: Calculation of characteristic points.

\subsection{Effect of Section Size on Seismic Performance}

3.4.1. Relative Nominal Flexural Strength. The ultimate moment considering the second-order effect is

$$
M=N \Delta+V H
$$

where $N$ is the axial load, $\Delta$ is the displacement, $V$ is the shear force, and $H$ listed in Table 4 is the total height of the column considering the spherical hinge.

The ratio of $M$ to $f_{c k} b h_{0}^{2}$ was used to infer the relative nominal flexural strength [27]. The relationship between the relative nominal flexural strength and the nominal angle of rotation is shown in Figure 12, which reflects the size effect on the relative nominal flexural strength. The nominal angle of rotation is given by $\Delta / H_{0}$, where $\Delta$ is the displacement of the column and $H_{0}$ is the theoretical height of the column. As shown in the figure, the relative nominal flexural strength exhibits a size effect at the maximum load and softening stages. The effect of section size on the relative nominal flexural strength at the maximum load is shown in detail in Figure 13. The relative nominal flexural strength decreased as the section size increased, except for the WF-3 specimen. Notably, for specimens with the shear span-to-depth ratio of 4 , the size effect was stronger than that of specimens with the shear span-to-depth ratio of 2 , which is in accordance with literature [17].

3.4.2. Analysis of Energy Dissipation Capacity. In this study, the equivalent viscous-damping ratio was used as an index to evaluate the energy dissipation ability of the specimens [32]. The relationship between the equivalent viscous-damping ratio and the nominal angle of rotation is shown in Figure 14, which shows that the equivalent viscous-damping ratio increased as the nominal angle of rotation increased. 
TABLE 6: Strain in longitudinal reinforcement and stirrups of WF specimens.

\begin{tabular}{|c|c|c|c|c|c|}
\hline Test no. & Load stage & $\varepsilon_{1}\left(\times 10^{-6}\right)$ & $\varepsilon_{z}\left(\times 10^{-6}\right)$ & $\varepsilon_{2}\left(\times 10^{-6}\right)$ & $\varepsilon_{g}\left(\times 10^{-6}\right)$ \\
\hline \multirow{4}{*}{ WF-3-2 } & \multirow{4}{*}{ Maximum load } & \multirow{4}{*}{$4895(21.5)$} & \multirow{4}{*}{2429} & $243(43)$ & \multirow{4}{*}{1752} \\
\hline & & & & $1031(86)$ & \\
\hline & & & & 488(129) & \\
\hline & & & & $697(172)$ & \\
\hline \multirow{4}{*}{ WF-5-2 } & \multirow{4}{*}{ Maximum load } & \multirow{4}{*}{$3118(177.5)$} & \multirow{4}{*}{2310} & $204(71)$ & \multirow{4}{*}{1779} \\
\hline & & & & $639(142)$ & \\
\hline & & & & $1102(213)$ & \\
\hline & & & & $736(284)$ & \\
\hline \multirow{4}{*}{ WF-7-2 } & \multirow{4}{*}{ Maximum load } & \multirow{4}{*}{$3530(50.0)$} & \multirow{4}{*}{2374} & 1279(100) & \multirow{4}{*}{1736} \\
\hline & & & & $326(200)$ & \\
\hline & & & & $1590(300)$ & \\
\hline & & & & $342(400)$ & \\
\hline \multirow{2}{*}{ WF-3-4 } & \multirow{2}{*}{ Maximum load } & \multirow{2}{*}{$2531(21.5)$} & \multirow{2}{*}{2429} & $1042(43)$ & \multirow{2}{*}{1752} \\
\hline & & & & $2199(86)$ & \\
\hline \multirow{2}{*}{ WF-5-4 } & \multirow{2}{*}{ Maximum load } & \multirow{2}{*}{$3345(35.5)$} & \multirow{2}{*}{2310} & $230(71)$ & \multirow{2}{*}{1779} \\
\hline & & & & $279(142)$ & \\
\hline \multirow{2}{*}{ WF-7-4 } & \multirow{2}{*}{ Maximum load } & \multirow{2}{*}{$2463(250)$} & \multirow{2}{*}{2374} & 1702(100) & \multirow{2}{*}{1736} \\
\hline & & & & $614(200)$ & \\
\hline
\end{tabular}

$\varepsilon_{1}$ and $\varepsilon_{2}$ : measured strain in the longitudinal bars and stirrups; $\varepsilon_{z}$ and $\varepsilon_{g}$ : yield strain in the longitudinal bars and stirrups. The number inside the parentheses represents the distance from the foot of the column to the gage location (in $\mathrm{mm}$ ).

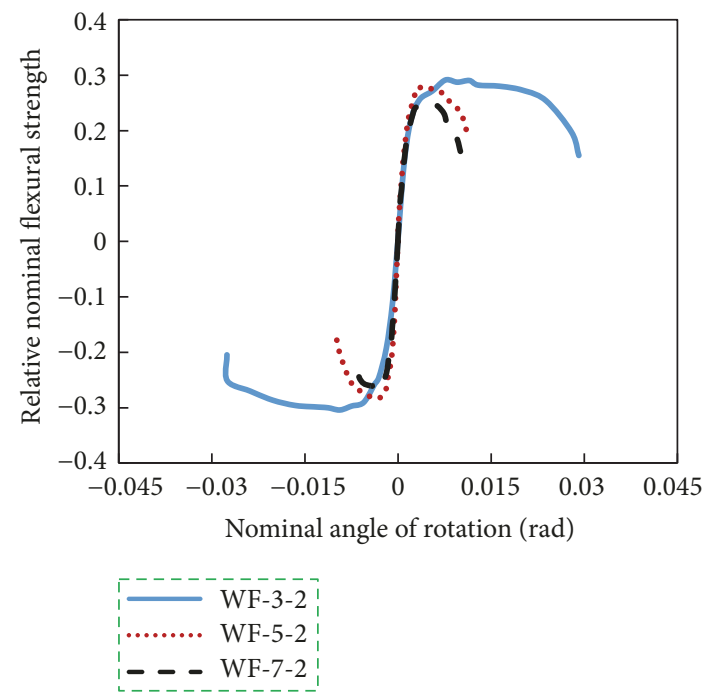

(a) Specimens with a shear span-to-depth ratio of 2

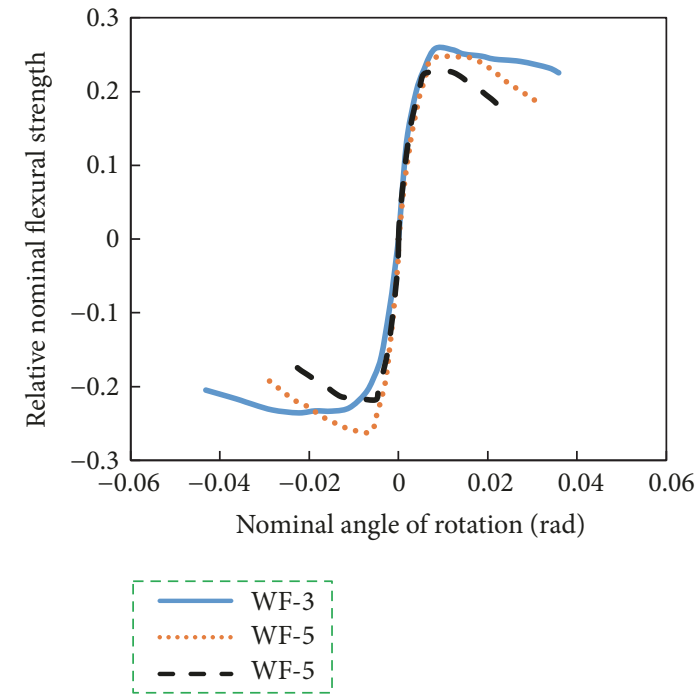

(b) Specimens with a shear span-to-depth ratio of 4

FIGURE 12: Relationship between relative nominal flexural strength and nominal angle of rotation.

This indicates that the energy dissipation capacity increases gradually with deflection. In order to evaluate the effect of section size on energy dissipation, the average energy dissipation coefficient proposed by Liang [33] was used as the evaluation index:

$$
\mu_{\mathrm{e}}=\frac{E}{m E_{y}}
$$

where $E$ is the total hysteresis loop area from yield load to failure load ( $85 \%$ of the maximum sustained load); $E_{y}=$ $P_{y} \Delta_{y} / 2$ is the equivalent elastic energy; $P_{y}$ and $\Delta_{y}$ are the yield load and yield displacement, respectively; and $m$ is the total number of cycles from yield load to failure load. The resulting average energy dissipation coefficients for different sized specimens are shown in Figure 15. The average energy dissipation coefficient was found to decrease as the section size increased. Overall, these results prove the existence of a 

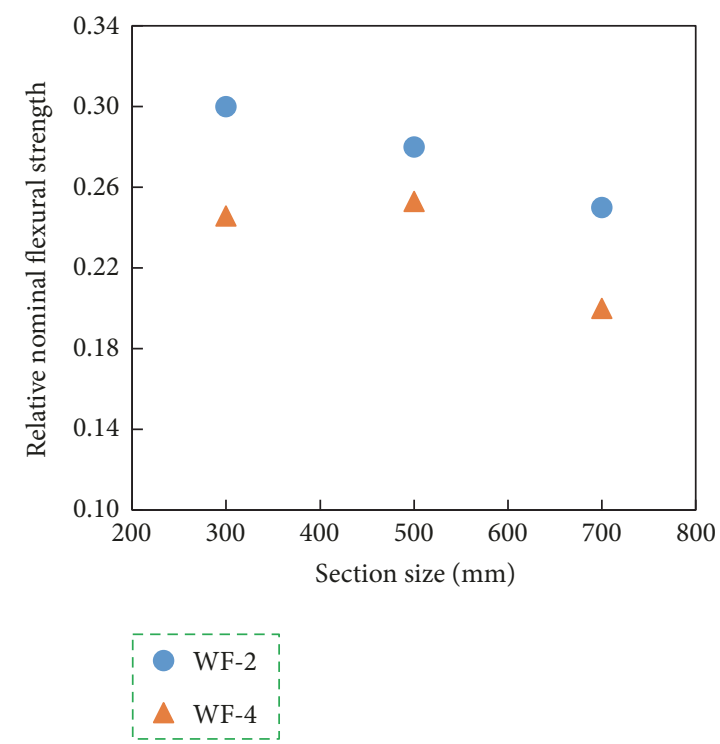

FIGURE 13: Relative nominal flexural strength for different section sizes.
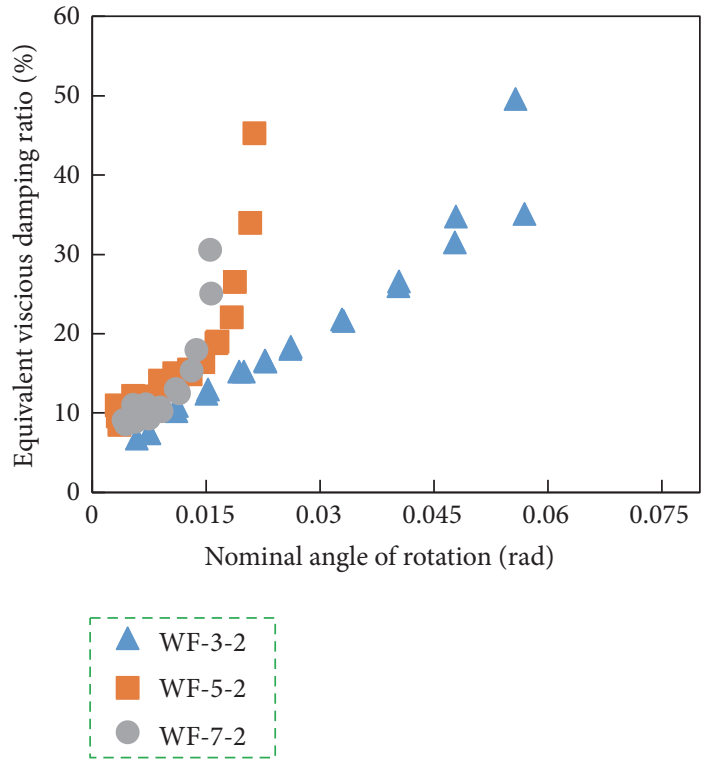

(a) Specimens with a shear span-to-depth ratio of 2
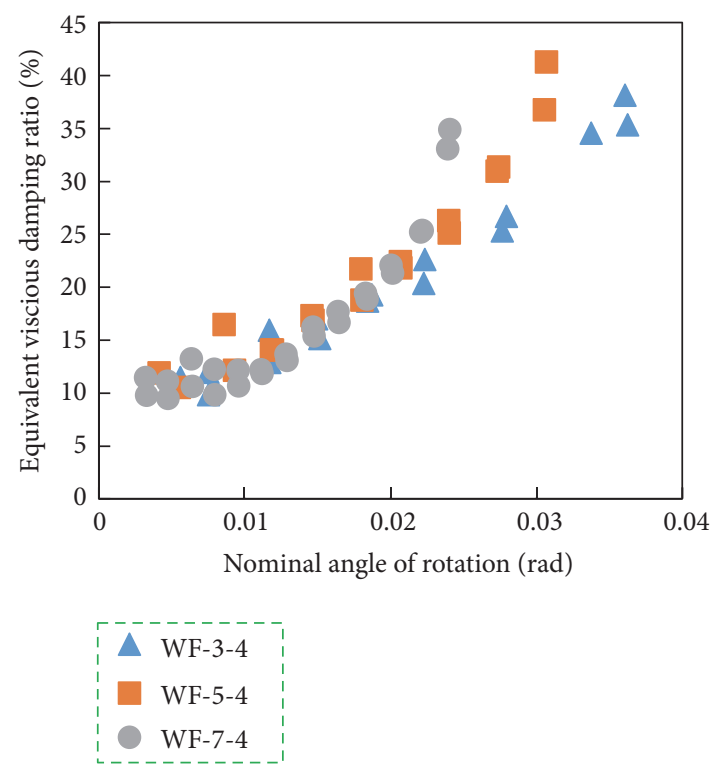

(b) Specimens with a shear span-to-depth ratio of 4

FIGURE 14: Relationship between average energy dissipation coefficient and section size.

size effect. Nevertheless, the results reveal that the size effect of shear span ratio on energy dissipation ability is not obvious.

\section{Effect of Section Size on Moment Capacity}

\subsection{Theoretical Calculation of Moment Capacity}

(1) Chinese Code for Design of Concrete Structures [4]. Table 6 shows that the strain in the tensile longitudinal bars reached the yield point due to bending, the strain in the compressive longitudinal bars reached the yield point due to the combined action of the axial load and bending, but the stirrups could not reach the yield point. This behavior conforms to the general moment capacity calculation method. A simple diagram for calculating moment capacity is shown in Figure 16. According to the balance of axial forces and moment about the centerline of the section, the equations for axial force $(N)$ and moment $\left(M_{\mathrm{c}}\right)$ are

$$
\begin{aligned}
N= & \alpha_{1} f_{\mathrm{ck}} b x+f_{\mathrm{yk}}{ }^{\prime} A_{\mathrm{s}}{ }^{\prime}+\sigma_{1}^{\prime} A_{\mathrm{s}}^{\prime}-\sigma_{1} A_{\mathrm{s}}-f_{\mathrm{yk}} A_{\mathrm{s}} \\
M_{\mathrm{c}}= & N e+V H \\
= & \alpha_{1} f_{\mathrm{ck}} b x\left(\frac{h}{2}-\frac{x}{2}\right)+\frac{1}{2} \sigma_{1}^{\prime} A_{\mathrm{s}}^{\prime} P_{0} \\
& +2 f_{\mathrm{yk}}^{\prime} A_{\mathrm{s}}{ }^{\prime}\left(\frac{h}{2}-a_{\mathrm{s}}^{\prime}\right)+\frac{1}{2} \sigma_{1} A_{\mathrm{s}} P_{0}
\end{aligned}
$$




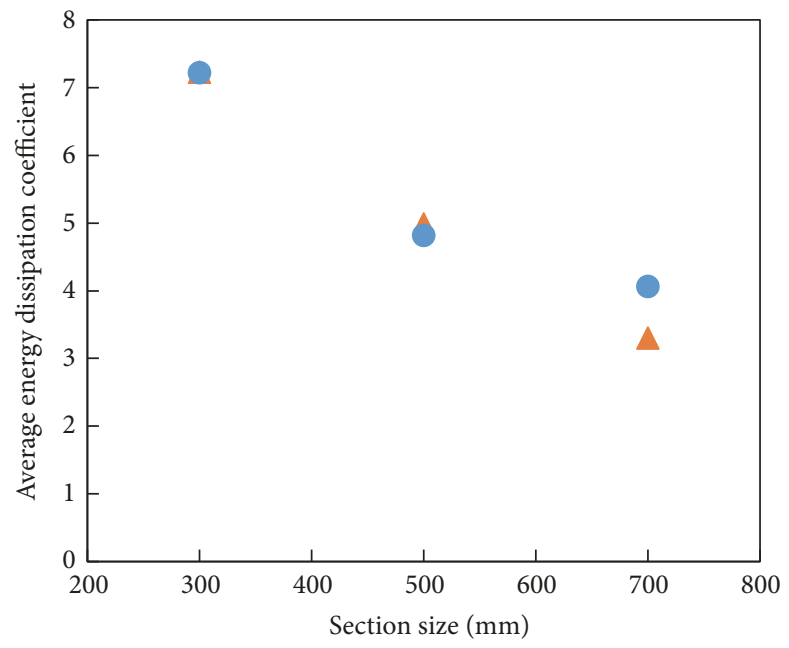

$\Delta \mathrm{WF}-2$

WF-4

FIGURE 15: Relationship between equivalent viscous- damping ratio and nominal angle of rotation.
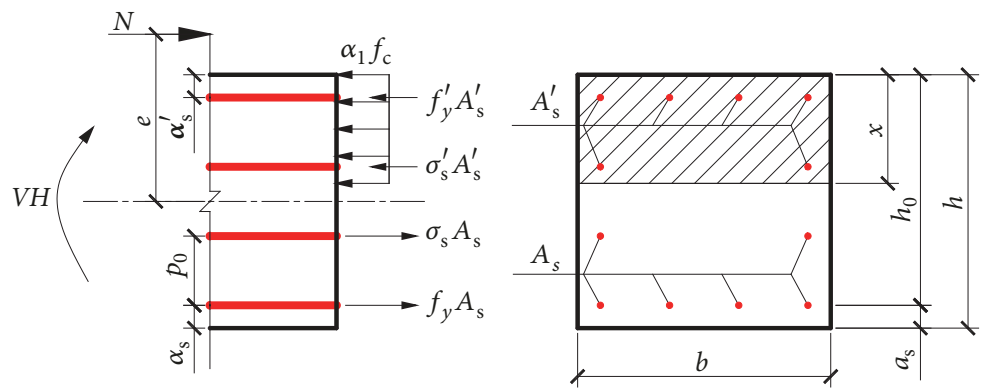

FIGURE 16: Calculation diagram of moment capacity.

and the stress in the longitudinal bars that have not yet reached the yield strain is given by

$$
\begin{aligned}
& \sigma_{s}=E_{\mathrm{s}} \varepsilon_{\mathrm{cu}}\left(\frac{\beta_{1}\left(h_{0}-p_{0}\right)}{x}-1\right) \\
& \sigma_{s}^{\prime}=E_{\mathrm{s}} \varepsilon_{\mathrm{cu}}\left(1-\frac{\beta_{1}\left(p_{0}+a_{s}^{\prime}\right)}{x}\right)
\end{aligned}
$$

where $\alpha_{1}$ is the ratio of the force in the equivalent rectangular compressive stress block to the axial compressive strength; $\beta_{1}$ is the ratio of the depth of equivalent rectangular compressive stress block to the distance of the fiber of maximum compressive strain from the neutral axis; $P_{0}$ is the distance between the longitudinal bars, and longitudinal bars spacing is uniform; $\varepsilon_{\mathrm{cu}}$ is the maximum usable strain; $x$ is the depth of the equivalent rectangular compressive stress block; $a_{\mathrm{s}}^{\prime}$ is the distance from the compressive longitudinal bar to the compressive face; $a_{\mathrm{s}}$ is the distance from the tensile longitudinal bar to the tensile face; $E_{\mathrm{s}}$ is the modulus of elasticity; $f_{\mathrm{yk}}$ and $f_{y k}^{\prime}$ are the yield strength of the longitudinal tension and compression bars, respectively; $A_{\mathrm{s}}$ and $A_{\mathrm{s}}^{\prime}$ are the crosssectional area of the longitudinal tension and compression bars, respectively; $f_{\mathrm{ck}}$ is the axial compressive strength; $e$ is the eccentric distance from the line of application of the axial load to the centerline of the section; $V$ is the applied horizontal load; and $H$ is the column height including the hinge.

The factor of safety $\alpha$ is defined as $M_{t} / M_{c}$, where $M_{t}$ is the experimentally determined moment capacity, $M_{\mathrm{t}}=N \Delta+$ $V H$ ( $N$ is the axial load, $\Delta$ is horizontal displacement, $V$ is the horizontal load, and $H$ is the total height including the hinge), and $M_{\mathrm{c}}$ is the theoretical moment capacity calculated using the Chinese code and given in (3). The resulting moments and factors of safety are given in Table 7 .

The resulting effect of section size on the factor of safety is shown in Figure 17. The factor of safety was found to decrease as the section size increased, indicating a strong size effect. Notably, the size effect became stronger as the shear span-to-depth ratio increased. These test results effectively confirm that the evaluated design codes are based on a limit state approach and thus neglect size effects. This leads to potentially unsafe large-sized components when they are 


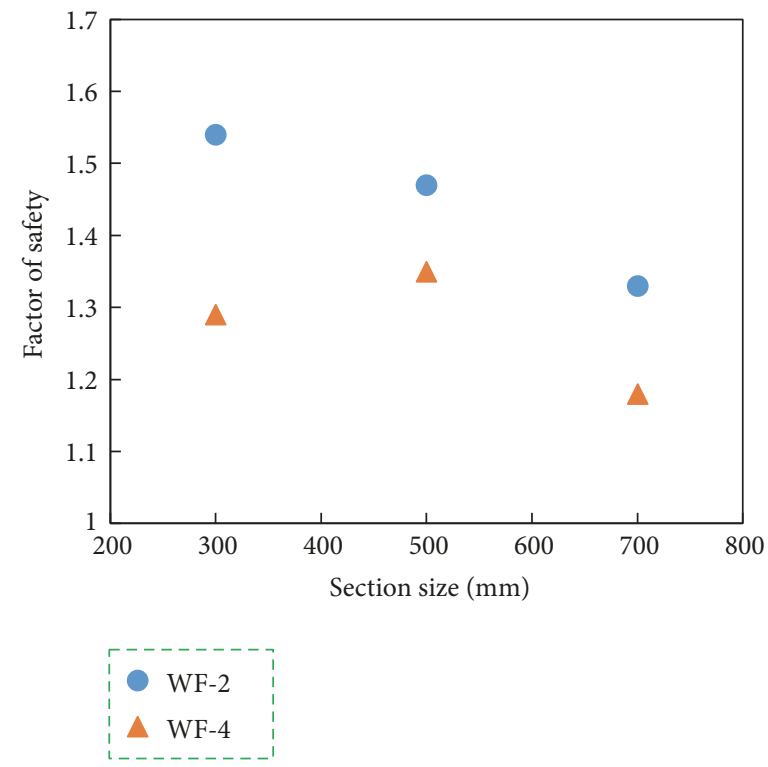

FIGURE 17: Comparison of factors of safety determined using different codes for calculating moment capacity.

TABLE 7: Factor of safety.

\begin{tabular}{lccc}
\hline Test no. & $M_{\mathrm{t}}[\mathrm{kN} \cdot \mathrm{m}]$ & $M_{\mathrm{c}}[\mathrm{kN} \cdot \mathrm{m}]$ & $M_{\mathrm{t}} / M_{\mathrm{c}}$ \\
\hline WF-3-2 & 324 & 211 & 1.54 \\
WF-5-2 & 1418 & 963 & 1.47 \\
WF-7-2 & 3530 & 2649 & 1.33 \\
\hline WF-3-4 & 274 & 213 & 1.29 \\
WF-5-4 & 1307 & 971 & 1.35 \\
WF-7-4 & 3146 & 2666 & 1.18 \\
\hline
\end{tabular}

designed in accordance with the Chinese code. To address this potentially unsafe design, the equations for calculating moment capacity should be modified.

4.2. Size Effect Analysis Based on Fracture Mechanics. In this study, the Type 2 size effect model proposed by Bažant [10] was used as the theoretical model for determining the size effect according to the analysis of failure modes. The Type 2 equation is

$$
\alpha_{\mathrm{hD}}=\frac{B f_{t}}{\sqrt{1+h / D_{0}}}
$$

where $h$ is the height of the section, $B$ is a dimensionless constant, $D_{0}$ is the size at which behavior transitions from ductile to brittle, and $f_{t}$ is the axial tensile strength of the concrete.

In order to obtain the two empirical parameters, $B$ and $D_{0},(7)$ can be rearranged into

$$
\left(\frac{f_{t}}{\alpha_{\mathrm{hD}}}\right)^{2}=\frac{1}{B^{2}}+\frac{h}{B^{2} D_{0}}
$$

which is of the form $Y=A X+C$, where $Y=\left(f_{t} / \alpha_{\mathrm{hD}}\right)^{2}$, $X=h, C=1 / B^{2}$, and $A=1 / B^{2} D_{0}$. Then $B$ and $D_{0}$ can be determined from a regression analysis according to the preceding factor of safety relationships.

For the specimens with the shear span-to-depth ratios of 2 and 4, the equation capturing the size effect in the form of (7) is therefore

$$
\begin{aligned}
& \alpha_{\mathrm{hD} 1}=\frac{0.5128 f_{t 1}}{\sqrt{1+h / 931.4}} \\
& \alpha_{h D 2}=\frac{0.7559 f_{t 2}}{\sqrt{1+h / 145.6}}
\end{aligned}
$$

where $f_{t 1}=3.48 \mathrm{MPa}$ and $f_{t 2}=3.76 \mathrm{MPa}$.

Then, (7) can also be expressed as

$$
\frac{\alpha_{\mathrm{hD}}}{B f_{t}}=\frac{1}{\sqrt{1+h / D_{0}}}
$$

To describe this effect in the current study, Figure 18 shows the relationship between the factor of safety and section size of the high-strength RC columns with different shear span-to-depth ratios, in which $\log \left(h / D_{0}\right)$ is plotted against $\log \left(\alpha_{\mathrm{hD}} / B f_{t}\right)$. The size effect appears to be stronger on specimens with the shear span-to-depth ratio of 4 than those with the shear span-to-depth ratio of 2; the response of the shear span-to-depth ratio of 4 to size lies closer the LEFM asymptote.

In order to check the fitting degree of the test results with the Type 2 size effect model [10], a correlation coefficient, $\rho_{\mathrm{XY}}=\operatorname{cov}(\mathrm{X}, \mathrm{Y}) / \sqrt{D(\mathrm{X})} \sqrt{D(\mathrm{Y})}$ where $X=h$ and $\mathrm{Y}=$ $\left(1 / \alpha_{h D}\right)^{2}$, was applied to evaluate the results. The correlation coefficient for the specimens of shear span-to-depth ratio of 2 is 0.97 . For the specimens of shear span-to-depth ratio of 4 , the correlation coefficient is 0.67 . The correlation coefficients of both types of concrete suggest a very strong correlation between test results and the Type 2 Bažant's model [10], indicating behavior consistent with the theoretical work of Bažant. 


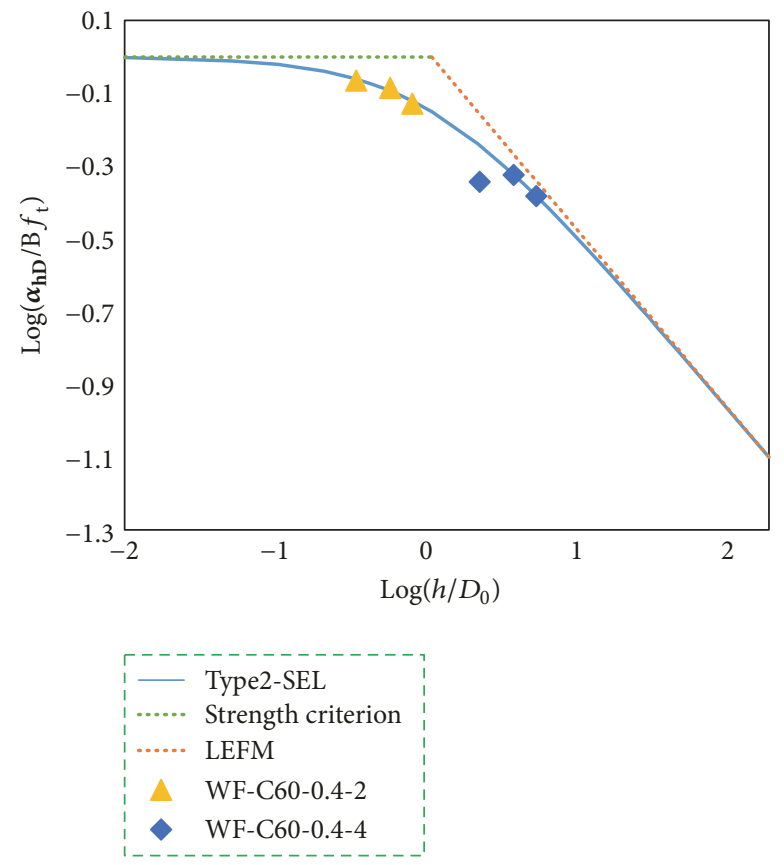

FIGURE 18: Effect of shear span-to-depth ratio on size effect.

TABLE 8: Local factor of safety calculated according to the Chinese code [4].

\begin{tabular}{lccc}
\hline Test no. & $M_{\mathrm{tc}}[\mathrm{kN} \cdot \mathrm{m}]$ & $M_{\mathrm{cc}}[\mathrm{kN} \cdot \mathrm{m}]$ & $M_{\mathrm{tc}} / M_{\mathrm{cc}}$ \\
\hline WF-3-2 & 267.8 & 154.3 & 1.74 \\
WF-5-2 & 1172.1 & 714.5 & 1.64 \\
WF-7-2 & 2850.5 & 1960.8 & 1.45 \\
\hline WF-3-4 & 217.9 & 156.4 & 1.39 \\
WF-5-4 & 1060.3 & 724.1 & 1.46 \\
WF-7-4 & 2466.9 & 1987.2 & 1.24 \\
\hline
\end{tabular}

4.3. Modification of Moment Capacity. In order to eliminate the effect of section size on the factor of safety, the Type 2 size effect model was used as a modification coefficient to improve the moment capacity calculated according to the Chinese code [4]. In many metals, the strength is not attributable to any size effect [34]. Therefore, the moment capacity that concrete shares should be modified using Bažant's Type 2 size effect model. This can be expressed as $\alpha_{c i} \alpha_{1} f_{\mathrm{ck}} b x(h / 2-x / 2)$, where $\alpha_{c i}$ is the size effect parameter.

First, the moment resistance provided only by the concrete is calculated according to the total tested moment capacity, $M_{\mathrm{tc}}$. Then, according to (4), the theoretical moment capacity of the concrete is calculated as $M_{\mathrm{cc}}$. The proportion $M_{\mathrm{tc}} / M_{\mathrm{cc}}$ is then defined as the local factor of safety. The resulting local factors of safety are provided in Table 8. Figure 19 describes the relationship between the local factor of safety and section size. As shown in the figure, the local factor of safety decreased as the section size increased, exhibiting a strong size effect. Furthermore, as the shear span-to-depth ratio increased the size effect became stronger, except for specimen WF-3-4.

Adopting the same method as applied to the factor of safety, $B$ and $D_{0}$ of Bažant's Type 2 size effect were recalculated. Due to a large error discretization of the WD3 data, the local factor of safety for this specimen was not considered in the data fitting. Then, for the specimens with the shear span-to-depth ratios of 2 and 4, the size effect equation can be expressed as

$$
\begin{aligned}
& \alpha_{c 1}=\frac{0.6076 f_{t 1}}{\sqrt{1+h / 666.2}} \\
& \alpha_{c 2}=\frac{2.331 f_{t 2}}{\sqrt{1+h / 14.28}}
\end{aligned}
$$

By dividing (12) and (13) by the local factor of safety, the size effect equation can be expressed as

$$
\begin{aligned}
& \alpha_{c 1}=\frac{0.6076 f_{t 1} / \sqrt{1+h / 666.2}}{\alpha_{c 01}} \\
& \alpha_{c 2}=\frac{2.331 f_{t 2} / \sqrt{1+h / 14.28}}{\alpha_{c 02}}
\end{aligned}
$$

where $\alpha_{\mathrm{c} 01}$ and $\alpha_{\mathrm{c} 02}$ are the local factor of safety of the minimum section size. 

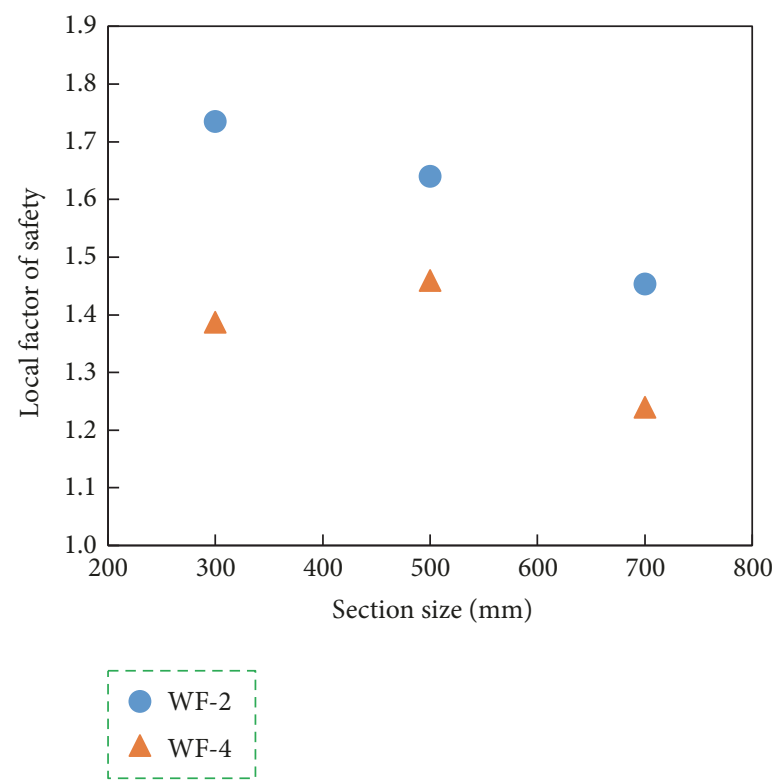

FIGURE 19: Local factor of safety for different section sizes.
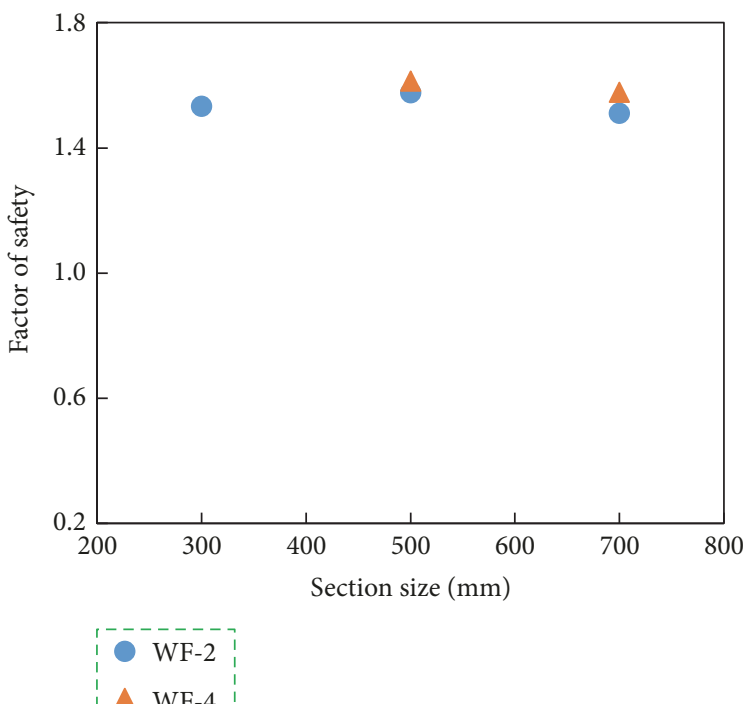

WF-4

FIgURE 20: Modified factor of safety using the proposed coefficient based on Bažant's Type 2 size effect model.

Introducing (14) and (15) into (4) provides a moment capacity equation accounting for the size effect as follows:

$$
\begin{aligned}
M_{\mathrm{c}}= & \alpha_{c i} \alpha_{1} f_{\mathrm{ck}} b x\left(\frac{h}{2}-\frac{x}{2}\right)+\frac{1}{2} \sigma_{1}^{\prime} A_{\mathrm{s}}^{\prime} P_{0} \\
& +2 f_{\mathrm{yk}}^{\prime} A_{\mathrm{s}}{ }^{\prime}\left(\frac{h}{2}-a_{s}^{\prime}\right)+\frac{1}{2} \sigma_{1} A_{\mathrm{s}} P_{0}
\end{aligned}
$$

where $\alpha_{c i}$ is the size effect parameter, $\mathrm{i}=1,2$. Using (16), the factors of safety are calculated again and are provided in Figure 20. Clearly, the modified factors of safety tend to be very consistent regardless of size, indicating that the moment capacity of larger-sized specimens will be as safe as those of smaller sized sections.

\section{Conclusions}

The effects of section size on the seismic performance of high-strength RC columns with different shear span-to-depth ratios were investigated experimentally using three columns of different sizes. The results verified the effects of size on the seismic performance of the columns with different shear span-to-depth ratios. The following conclusions can be drawn.

(1) The moment capacity of columns with shear spanto-depth ratios of 2 and 4 can be calculated according to flexural failure under the condition of providing sufficient shearing force of the columns. Meanwhile, the horizontal shear force exhibits a roughly inverse linear relationship 
with the shear span-to-depth ratio. In addition, the effect of shear span-to-depth ratio on the ductility of columns was not obvious, but as the shear span-to-depth ratio decreased, the strength degradation factor became more pronounced. However, short columns were inevitably formed in structure. Thus, for the safety of the structure, short columns with a shear span-to-depth ratio of 2 might need to be strengthened, such as the use of higher yield strength of stirrup and the increase of the volume-stirrup ratio.

(2) The seismic performance of high-strength RC columns was found to exhibit a strong size effect in which the relative nominal flexural strength, average energy dissipation coefficient, factor of safety, and local factor of safety all decreased as the section size was increased. Moreover, the size effect on the factor of safety was stronger for high-strength RC columns with shear span-to-depth ratio of 4 than those with shear span-to-depth ratio of 2, except for average energy dissipation coefficient.

(3) The change in the factor of safety with size was in good agreement with the Type 2 size effect model proposed by Bažant.

(4) Based on the test results and the Type 2 size effect model, the typical code equation for moment capacity was modified and the resulting equation was shown to provide a consistent factor of safety regardless of member size.

The experimental results presented in this study should serve as an important research database supporting the study of the size effect on high-strength RC columns with different shear span-to-depth ratios. Nevertheless, it is noteworthy that the present study focused on the size effect with respect to the effect of shear span-to-depth ratio. Therefore, further study on the influence of the volume-stirrup ratio, strength of stirrup reinforcement, and axial compression ratio on the size effect in high-strength RC columns will be conducted in the future.

\section{Data Availability}

The program and experimental data used to support the findings of this study are available from the corresponding author upon request.

\section{Conflicts of Interest}

The authors declare that there are no conflicts of interest regarding the publication of this paper.

\section{Authors' Contributions}

Zhenbao Li, Chunyi Yu, Hua Ma, Yongping Xie, and Zhenyun Tang conceived the idea of the study. Chunyi Yu conducted the experiments and analyzed the results. Chunyi $\mathrm{Yu}$, Zhenbao Li, and Yongping Xie translated the article, analyzed the results, and formatted the manuscript. All the authors interpreted and discussed the experimental results and provided substantive comments. All the authors were gratefully acknowledged.

\section{Acknowledgments}

This work was supported by the Science Fund for Creative Research Groups of the National Natural Science Foundation of China (no. 51408378) and Natural Science Foundation of Hebei Province (no. E2015403018).

\section{References}

[1] L. Jin, S. Zhang, D. Li, H. Xu, X. Du, and Z. Li, "A combined experimental and numerical analysis on the seismic behavior of short reinforced concrete columns with different structural sizes and axial compression ratios," International Journal of Damage Mechanics, vol. 27, no. 9, pp. 1416-1447, 2017.

[2] W. Zhuang, Z. Liu, and J. Jiang, "Earthquake-induced damage analysis of highway bridges in Wenchuan earthquake and countermeasures," Yanshilixue Yu Gongcheng Xuebao/Chinese Journal of Rock Mechanics and Engineering, vol. 28, no. 7, pp. 1377-1387, 2009.

[3] L.-S. Huo, H.-N. Li, S.-Y. Xiao, and D.-S. Wang, "Earthquake damage investigation and analysis of reinforced concrete frame structures in Wenchuan earthquake," Dalian Ligong Daxue Xuebao/Journal of Dalian University of Technology, vol. 49, no. 5, pp. 718-723, 2009.

[4] National Standards of the People's Republic of China, National Standards of the People's Republic of China, GB 50010-2010, Code for design of concrete structures, National Standards of the People's Republic of China, Beijing, China, 2011.

[5] American Concrete Institute, Building Code Requirements for Structural Concrete (ACI 318-14) and Commentary (ACI 318R14) by ACI Committee 318, Farmintog, Farmintog, Hills, MI, USA, 2014.

[6] Z. Bažant and E. P. Chen, "Scaling of structural failure," Advances in Mechanics, vol. 50, no. 10, pp. 593-627, 1990.

[7] A. A. Griffith, "The phenomena of rupture and flow in solids," Philosophical Transactions of the Royal Society of London, vol. 221, no. 2, pp. 163-198, 1921.

[8] W. Weibull, "Phenomenon of rupture in solids," Ingenioersvetenskaps Akad Handl, vol. 153, pp. 1-55, 1939.

[9] W. Weibull, "A statistical distribution functions of wide application," Journal of Applied Mechanics, vol. 18, pp. 293-297, 1951.

[10] Z. P. Bažant, "Size effect in blunt fracture: Concrete, rock, metal," Journal of Engineering Mechanics, vol. 110, no. 4, pp. 518-535, 1984.

[11] A. Carpinteri and G. Ferro, "Size effects on tensile fracture properties: a unified explanation based on disorder and fractality of concrete microstructure," Materials and Structures, vol. 27, no. 10, pp. 563-571, 1994.

[12] Z. P. Baant and G. Lewis, Scaling of Structural Strength, Elsevier, Oxford, 2nd edition, 2005.

[13] Z. P. Bažant and Q. Yu, "Universal size effect law and effect of crack depth on quasi-brittle structure strength," Journal of Engineering Mechanics, vol. 135, no. 2, pp. 78-84, 2016.

[14] C. G. Hoover and Z. P. Bažant, "Universal size-shape effect law based on comprehensive concrete fracture tests," Journal of Engineering Mechanics, vol. 140, no. 3, pp. 473-479, 2014.

[15] S. Şener, "Size effect tests of high strength concrete," Journal of Materials in Civil Engineering, vol. 9, no. 1, pp. 46-48, 1997.

[16] J. Su and Z. Fang, "Scale effect on cubic compressive strength of ordinary concrete and high-strength concrete," Jianzhu Cailiao Xuebao/Journal of Building Materials, vol. 16, no. 6, pp. 10781086, 2013. 
[17] K.-H. Yang, H.-S. Chung, E.-T. Lee, and H.-C. Eun, "Shear characteristics of high-strength concrete deep beams without shear reinforcements," Engineering Structures, vol. 25, no. 10, pp. 1343-1352, 2003.

[18] Q. Yu and Z. P. Bažant, "Can Stirrups Suppress Size Effect on Shear Strength of RC Beams?" Journal of Structural Engineering, vol. 137, no. 5, pp. 607-617, 2011.

[19] M. P. Collins and D. Kuchma, "How safe are our large, lightly reinforced concrete beams, slabs, and footings?" ACI Structural Journal, vol. 96, no. 4, pp. 482-490, 1999.

[20] L. Jin, D. Li, and X. Du, "Mechanical behavior and size effect of moderate high-strength RC columns under monotonic and cyclic axial compression," Engineering Structures, vol. 124, pp. 269-285, 2016.

[21] C. Xu, L. Jin, Z. Ding, D. Li, and X. Du, "Size effect tests of highstrength RC columns under eccentric loading," Engineering Structures, vol. 126, pp. 78-91, 2016.

[22] Z. P. Bažant and Y. W. Kwon, "Failure of slender and stocky reinforced concrete columns: tests of size effect," Materials and Structures, vol. 27, no. 2, pp. 79-90, 1994.

[23] Z. Li, E. Guo, X. Zhou, X. Du, and H. Zhou, "Seismic behaviors and size effects of large-scale interior beam-column joints of RC frames," Tumu Gongcheng Xuebao/China Civil Engineering Journal, vol. 45, no. 7, pp. 39-47, 2012.

[24] S. Barbhuiya and A. M. Choudhury, "A study on the size effect of RC beam-column connections under cyclic loading," Engineering Structures, vol. 95, pp. 1-7, 2015.

[25] D. Li, L. Jin, X. Du, J. Fu, and A. Lu, "Size effect tests of normal-strength and high-strength RC columns subjected to axial compressive loading," Engineering Structures, vol. 109, pp. 43-60, 2016.

[26] X. Du, L. Jin, and D. Li, "A state-of-the-art review on the size effect of concretes and concrete structures (I): concrete materials," Tumu Gongcheng Xuebao/China Civil Engineering Journal, vol. 50, no. 9, pp. 28-45, 2017.

[27] Z. B. Li, Y. P. Xie, X. L. Du, H. Ma, E. W. Guo, and Y. Zhang, "Experimental study on size effect of seismic behavior for reinforced concrete columns under Monotonic horizontal loading," Journal of Building Structures, vol. 34, no. 12, pp. 7785, 2013.

[28] Z. B. Li, Y. P. Xie, X. L. Du, and Y. Q. Zhai, "Size effect on shear behavior of reinforced concrete short columns," Journal of Building Structures, vol. 34, no. 12, pp. 86-93, 2013.

[29] Y. Xie, Z. Li, X. Du, H. Ma, E. Guo, and L. Chen, "Experimental study on size effect of seismic behavior for reinforced concrete columns under low cycle reversed loading," Jianzhu Jiegou Xuebao/Journal of Building Structures, vol. 34, no. 12, pp. 86-93, 2013.

[30] National Standards of the People's Republic of China, GB 500812002, Standard for test method of mechanical properties on ordinary concrete, National Standards of the People's Republic of China, Beijing, China, 2003.

[31] National Standards of the People's Republic of China, GB/T 228.1-2010, Metallic materials-Tensile testing-Part 1: Method of test at room temperature, National Standards of the People's Republic of China, Beijing, China, 2003.

[32] National Standards of the People's Republic of China, JGJ/T 101-2015, Specification for seismic test of buildings, National Standards of the People's Republic of China, Beijing, China, 2003.
[33] S. T. Liang, D. J. Ding, and Q. Lu, "Experimental study of earthquake resistant energy dissipation and ductility of reinforced concrete column hinge with composite stirrups," Industrial Construction, vol. 123, no. 11, pp. 16-20, 1994.

[34] Z. P. Bažant and Y. Xiang, "Size effect in compression fracture: splitting crack band propagation," Journal of Engineering Mechanics, vol. 123, no. 2, pp. 162-172, 1997. 


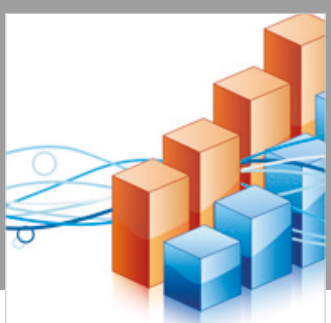

Advances in

Operations Research

\section{-n-m}
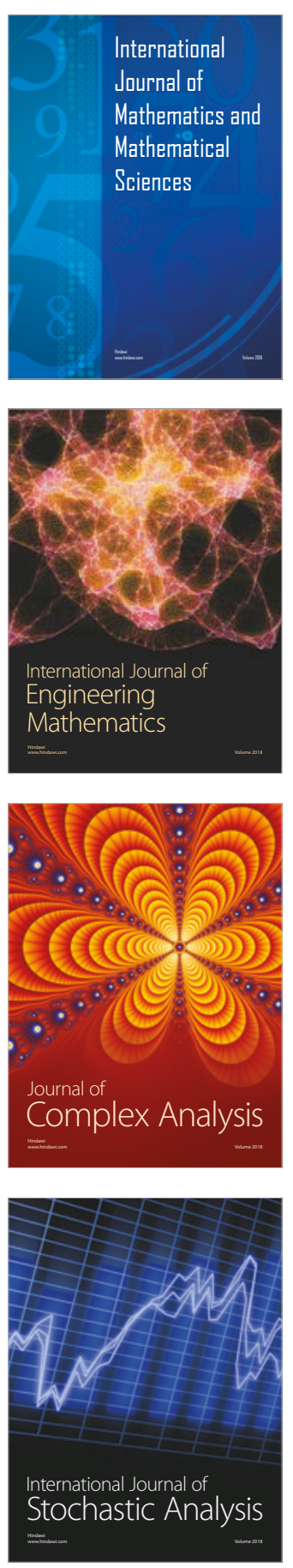
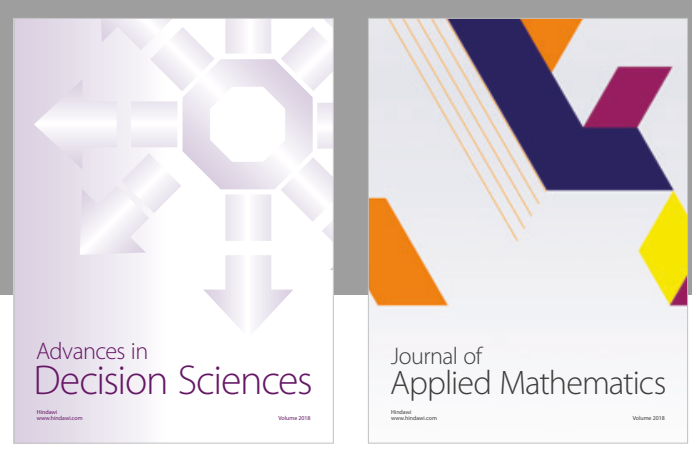

Journal of

Applied Mathematics
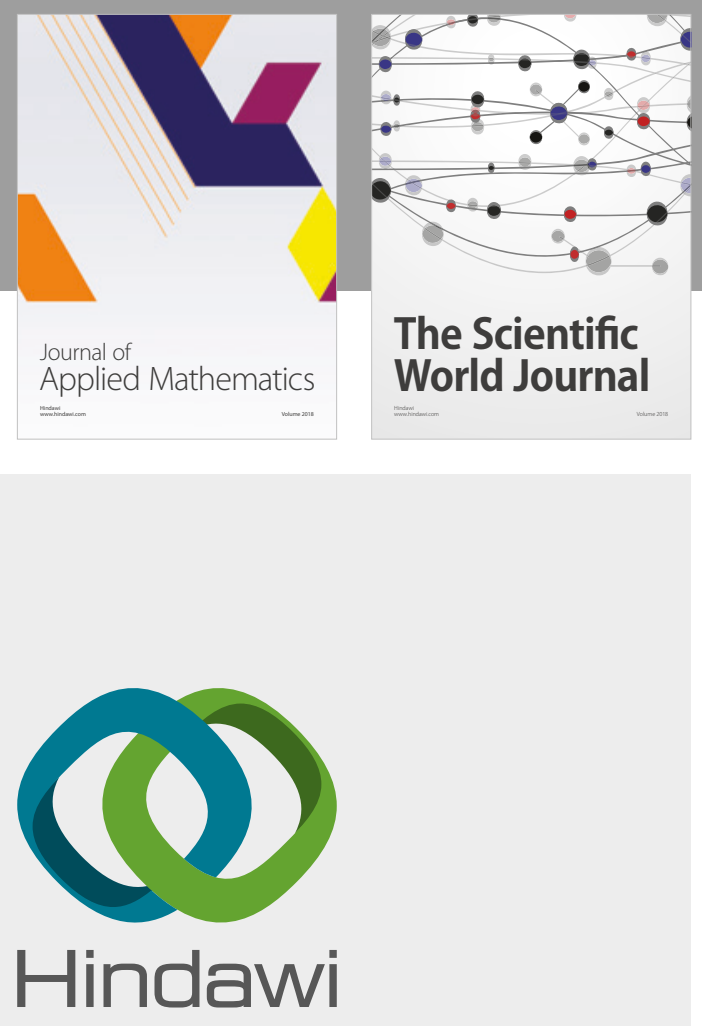

Submit your manuscripts at

www.hindawi.com

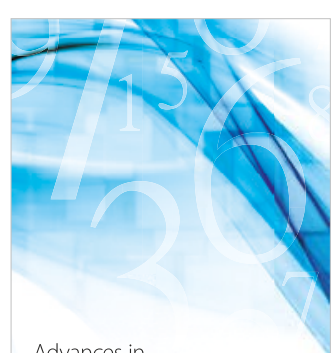

Advances in
Numerical Analysis
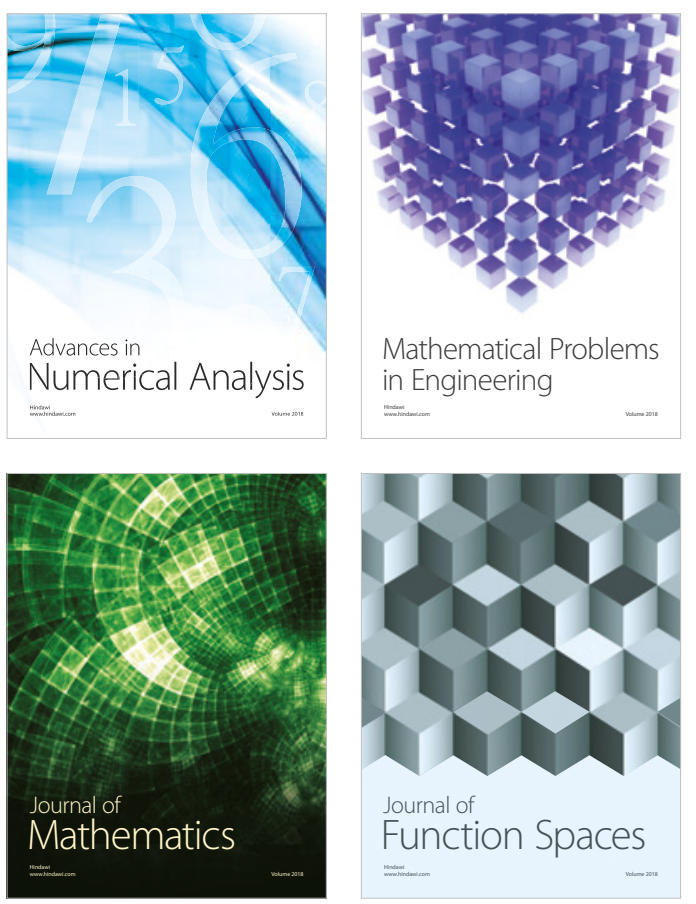

Mathematical Problems in Engineering

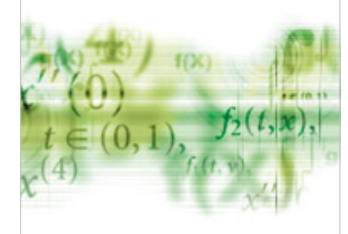

International Journal of

Differential Equations

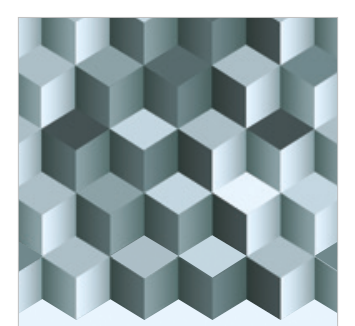

Journal of

Function Spaces

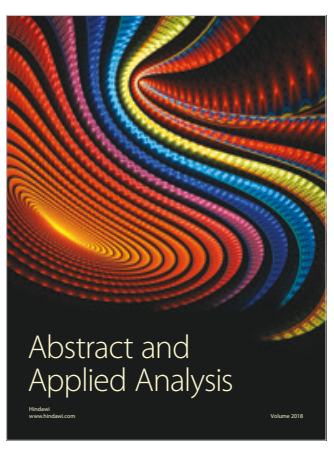

The Scientific

World Journal

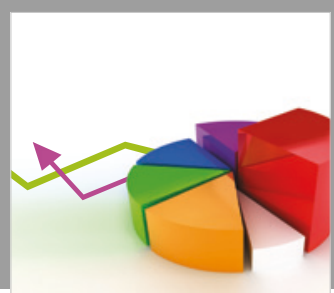

Journal of

Probability and Statistics
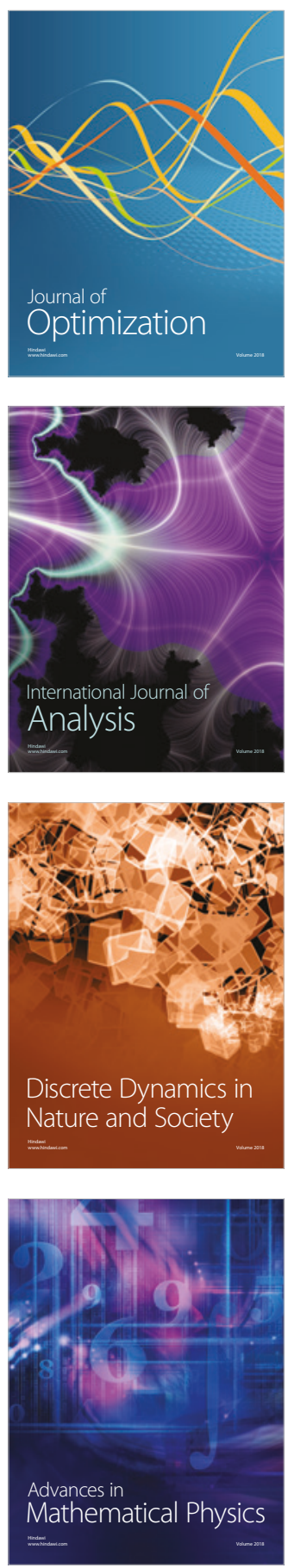